\title{
AN ATTENTIONAL THEORY OF ISSUE-CARRYING CAPACITY
}

A Dissertation presented to

the Faculty of the Graduate School

at the University of Missouri

In Partial Fulfillment

of the Requirements for the Degree of

Doctor of Philosophy

by

TEVFIK MURAT YILDIRIM

Dr. Laron K. Williams, Dissertation Supervisor

July 2018 
The undersigned, appointed by the Dean of the Graduate School, have examined the dissertation entitled:

\section{AN ATTENTIONAL THEORY OF ISSUE-CARRYING CAPACITY}

presented by Tevfik Murat Yildirim, a candidate for the degree of Doctor of Philosophy and hereby certify that, in their opinion, it is worthy of acceptance.

Dr. Laron K. Williams

Dr. L. Marvin Overby

Dr. Jonathan Krieckhaus

Dr. Lael R. Keiser 


\section{ACKNOWLEDGMENTS}

The argument that attention is a scarce resource is not simply the main premise that my theoretical expectations in this dissertation build on; it is an important and inevitable fact in our lives. For this reason, those who have shared this scarce resource with me during my time at the University of Missouri deserve to be acknowledged. First of all, I thank Laron K. Williams for teaching me so much about the discipline and academia; I always felt lucky to be supervised by him. I thank Marvin Overby for his invaluable advices and constant encouragement; I have not met another person who is more encouraging and motivating as him. I have learned so much from Lael Keiser and Jonathan Krieckhaus about professionalism and surviving the graduate school, for which I am truly grateful. I am also grateful for Audra Jenkins, who has spent considerable time trying to answer my endless questions about the bureaucratic procedures in the department.

Part of this research would not be made possible without the support of various individuals and organizations. I would like to thank the Kinder Institute on Constitutional Democracy for providing me with generous grants that allowed me to gather and code legislative activities within the framework of the Comparative Agendas Project. I thank Frank R. Baumgartner, Bryan D. Jones and Marvin Overby for mentoring me in my research on policy agendas and for supporting the creation of the Turkish Policy Agendas Project. I also thank Goker Bilgic for providing excellent research assistance in the coding of thousands of parliamentary speeches.

My greatest debts are owed to my wife, Işıl, who has patiently supported me throughout this entire process and to my parents, Emel and Muhsin Yildirim, who have invested so much in me in every possible way. I could not have made it through this challenging experience without their support. 
TABLE OF CONTENTS

ACKNOWLEDGMENTS .................. ii

LIST OF TABLES $\ldots \ldots \ldots \ldots \ldots \ldots \ldots \ldots \ldots \ldots$

LIST OF FIGURES $\ldots \ldots \ldots \ldots \ldots \ldots \ldots$ vii

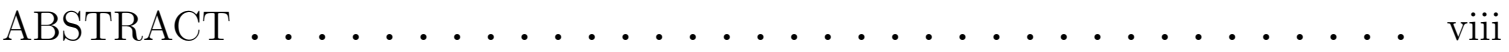

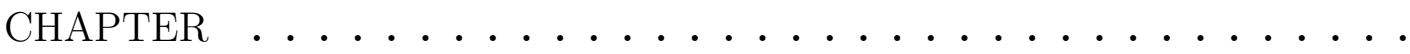

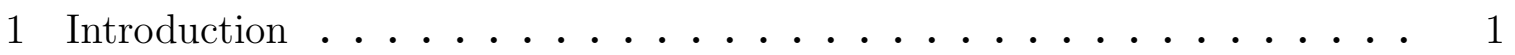

1.1 Background $\ldots \ldots \ldots \ldots \ldots \ldots \ldots \ldots \ldots \ldots \ldots \ldots \ldots$

1.2 Outline . . . . . . . . . . . . . . . . . . . . . 9

2 An Attentional Theory of Issue-Carrying Capacity . . . . . . . . . . . 12

2.1 Information Processing and Cognitive Styles . . . . . . . . 13

2.2 Gender Differences in Cognitive Styles and Attention . . . . . . . 15

2.2.1 Social Roles, Norms and Values . . . . . . . . . . . . . 15

2.2.2 Brain, Cognition and Emotional Memory . . . . . . . . . . 18

2.2.3 Information Processing in Political Behavior Research . . . . . 24

2.2.4 Hypotheses and Empirical Approach . . . . . . . . . 26

2.3 Do Women Show More Concern for Societal Issues? . . . . . . . . . . 29

3 Gender Differences in Policy Priorities . . . . . . . . . . . . 32

3.1 Selective Attention to Feminine-Masculine Issues . . . . . . . . . . . 34

3.2 Data and Methods ... . . . . . . . . . . . 38

3.3 Results . . . . . . . . . . . . . . . . . . . . . . . . . . . 39

3.4 The Saliency of 'Feminine-Masculine' Issues: A Difficult Case . . . . . 44

3.5 Discussion . . . . . . . . . . . . . . . . . . 46 
4 Gender, Cognitive Styles and the Most Important Problems . . . . . . . . 49

4.1 A Brief Overview of Theoretical Expectations . . . . . . . . . . 50

4.2 Study I: Evidence from 12 European Countries . . . . . . . . . . . . . 51

4.2.1 Data and Methods ................. 51

4.2.2 Results.......................... 53

4.3 Study II: Evidence from the US . . . . . . . . . . . . . . . 56

4.3.1 Data and Methods ................. 56

4.3.2 Results.......................... 58

4.4 Discussion . . . . . . . . . . . . . . . . . . . . . . 61

5 Representatives' Information Processing . . . . . . . . . . . . 64

5.1 The Turkish Case . . . . . . . . . . . . . . . . . . . 65

5.2 Data and Methods . . . . . . . . . . . . . . 67

5.3 Results............................. 68

5.3.1 Additional Analyses . . . . . . . . . . . . . . . . 70

5.4 Discussion . . . . . . . . . . . . . . . . . . . . . 72

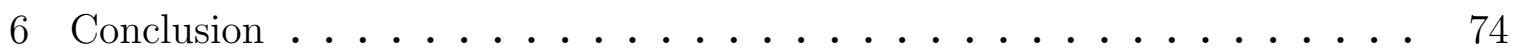

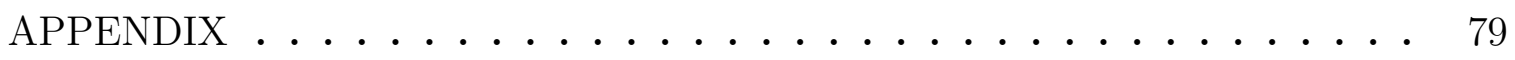

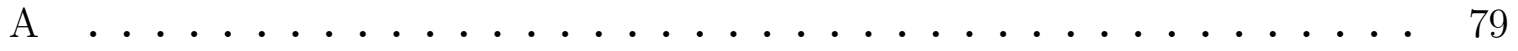

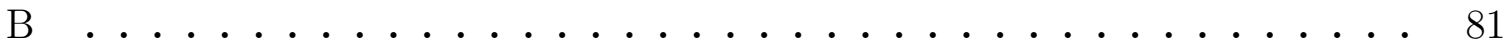

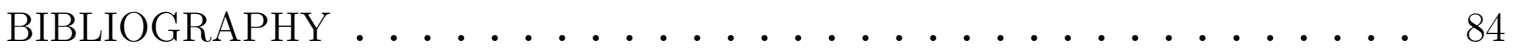

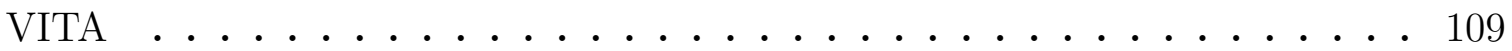




\section{LIST OF TABLES}

Table $\quad$ Page

2.1 A Hypothetical Distribution of Legislative Speeches and Diversity Scores by Legislators . . . . . . . . . . . . . . . . . . . . . . . . . 28

3.1 Gender Differences in Attention to Feminine and Masculine Issues . . 41

4.1 Summary Statistics of the Variables . . . . . . . . . . . . . . . 52

4.2 Multilevel Mixed-Effects Poisson Regression on the Number of Most Important Problems . . . . . . . . . . . . . . . . . . . 55

4.3 Measurement of Dependent and Independent Variables . . . . . . . . 58

4.4 Poisson Regression on the Number of Most Important Problems . . . 60

5.1 The Political and Demographic Characteristics of Representatives . . 69

5.2 The Effect of Gender on Entropic Agenda . . . . . . . . . . . . . . . 71

A.1 Summary Statistics . . . . . . . . . . . . . . . . 79

A.2 The Number of Respondents by Survey Organization . . . . . . . . . 80

B.1 Summary Statistics based on the New Sample (1999-2002, female only) 81

B.2 Summary Statistics based on the New Sample (1999-2002, male only) 81

B.3 Summary Statistics based on the Original Sample (2002-2011, female

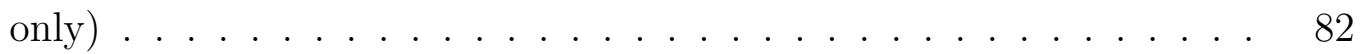

B.4 Summary Statistics based on the Original Sample (2002-2011, male only) 82 
B.5 The Effect of Gender on Agenda Diversity (1999-2011) _ . . . . . 83

B.6 The Effect of Gender on Agenda Diversity (1999-2002 only) . . . . 83 


\section{LIST OF FIGURES}

$\begin{array}{ll}\text { Figure } & \text { Page }\end{array}$

2.1 Biosocial Construction Model . . . . . . . . . . . . . . . . 17

2.2 Gender Differences in Attention to Social Problems . . . . . . . . . . 30

3.1 Gender Differences in Individual Policy Areas . . . . . . . . . . . . . 42

3.2 Gender Differences in Masculine and Feminine Issues by Decade . . . 43 


\section{ABSTRACT}

A plethora of research in cognitive and behavioral psychology showed that there are significant differences in the way men and women process political and social information. It has been widely accepted that women show more social concern for and tend to be more reactive to the problems in their social environments. The potential implications of these distinct cognitive styles, however, have received scant academic attention in political science research. In particular, we have scant knowledge of the extent to which differing cognitive styles affect the scope of problem identification and prioritization. Integrating insights from both political behavior and psychology research, this dissertation argues that women's lower cognitive threshold of urgency for societal issues should have important political implications. More specifically, I argue that, compared with their male counterparts, female decision makers should attend to a wider variety of societal issues facing their country. My empirical strategy is two-fold. First, with over 930,000 respondents over the past 75 years in the US, I undertake the most comprehensive test of gender differences in issue attention and show that such differences are much stronger than previously thought and invariant across time. Second, utilizing the European Election Study surveys conducted in 12 European countries $(\mathrm{N}=13,549), 94$ nationally representative surveys conducted between 1960 and 2015 in the US $(\mathrm{N}=110,796)$, and original datasets of legislative speeches from Turkey, I test the argument that women differ from men in the scope of societal issues with which they are involved and find strong empirical evidence for it. Results show that women do indeed attend to a broader range of issues when asked about the most important problems facing their country and speak about a wider range of issues in legislatures, a finding that is insensitive to various alternative model specifications and robustness tests. 


\section{Chapter 1}

\section{Introduction}

Emotion and empathy, some of humans' main characteristics that have evolved over millions of years, have been at the core of various interrelations that exist within and between social and political phenomena since the beginning of the modern political thought. Much of politics today is about how political elites and voters signal and receive messages regarding the issues facing their society, and emotion plays a starring role in this complex interplay (Westen 2008; Goodwin, Jasper and Polletta 2009; Marcus 2010). As cognitive psychologist George Lakoff (2008, 43) succintly puts it, most political phenomena are shaped by what has been increasingly called the 'political unconscious', "the system of concepts that structure our brains but that we can't see directly." Additionally, the political unconscious, Lakoff further argues, varies greatly by individual traits and 'modes of thought'. As an example, heated debates about whether poverty and social assistance are moral issues has dominated much of the politics of welfare in the US over the past several decades. In an Op-Ed piece published in National Review, a conservative journalist David A. French wrote that "anti-poverty policies and actions are doomed if their primary goal is to make a life of bad decisions more sustainable and comfortable." A similar opinion has been expressed by David Brooks in an Op-Ed in New York Times (2015): "The health of 
society is primarily determined by the habits and virtues of its citizens." Political scientist Martin Gilens (2009) shows that the media's tendency to portray the black poor in a negative light explains why Americans dislike the welfare programs. Still, large sections of voters support welfare spending and consider helping the poor as an important moral duty. If there are substantial variations in perceptions of societal problems among those who are exposed to similar streams of information (e.g., media portrayal), then voters' individual traits may determine the prioritization of these problems independent of external factors.

Societies face complex issues such as terror, crime and unemployment simultaneously. One of the received wisdom in the study of social sciences is that attention is a scarce resource; therefore, the prioritization of particular problems over others is crucial and it requires some form of ranking of 'issue importance'. While we are born to empathize and show concern for problems facing others, the degree to which one empathizes with problems facing society may vary across personality traits. Some of us may be concerned with the difficulties facing the poor, while some others may find the economic impact of excessive spending on welfare programs more troubling. Because attention is limited, one may devote particular attention to rising prices while ignoring other complex problems facing society such as the climate change, or issues related to health insurance and education. If the scope of societal issues with which individual human beings are involved varies by individual characteristics, this would have significant implications for various political phenomena, from electoral accountability to public policymaking. Moreover, such individual-level differences may translate into institutional outcomes, as "the connection between individual information-processing and organizational information-processing is not metaphorical; it is causal" (Jones and Baumgartner 2005, 42).

Are individual-level differences in information processing significant? If so, what causes such differences? Any attempt to advance our understanding of the differences 
in individual-level information processing must offer a systematic acount of their existence. In this dissertation, I explore one of the oft-cited determinants of individuallevel differences in information processing: gender. Building on the well-documented gender differences in the processing of information about the external environment, this dissertation makes the first attempt to examine the degree to which women differ from men in the range of issues they happen to attend to. As I will show in the chapters to follow, various strands of research in social, cognitive and neuropsychology have documented strong evidence that there are significant gender differences in the way human beings process information about societal issues. I will argue that these well-documented differences have important implications for the study of political behavior and policy processes. Drawing on various strands of research in political science and social, cognitive and behavioral psychology, this dissertation focuses on how women differ from men in the prioritization of problems facing their society. The key finding presented in this dissertation is that female legislators and voters, compared with their male counterparts, attend to a wider range of societal issues. In other words, a wider range of issues cross women's cognitive threshold of urgency for action. Using public opinion polls that were conducted in the US and 12 European countries, and original data of legislative speeches from the Grand National Assembly of Turkey, I show that gender differences are not time- and context-driven.

\section{$1.1 \quad$ Background}

In his seminal work, Herbert Simon (1985) described decision-makers, whether representatives or voters, as 'boundedly rational'; they have selective attention spans due to the "biological necessity of human decision-makers to process cognitive information serially" (Jones 1994). This 'serial information processing', the inability to attend a wide variety of issues simultaneously, results in "disproportionate informa- 
tion processing" (Jones 2001; Jones and Baumgartner 2005). In this view, regardless of the incentives provided by the external environment, human decision makers will pay excessive attention to some issues while ignoring others.

The notion of limited, or bounded, rationality has long been at the core of models of choice. A large strand of research following the work of Lindblom (1959) and Wildavsky (1964) contended that changes in governmental outputs such as budget allocations follow incremental patterns. According to this view, limited rationality coupled with complexity and uncertainty lead decision makers to make incremental changes when faced with pressure for change. The incrementalist approach had dominated models of policy choice until Baumgartner and Jones (1993) introduced the punctuated equilibrium framework, which has attracted utmost scholarly attention. Jones and Baumgartner $(2012,1)$ summarized the birth of this new approach as follows: "Punctuated Equilibrium Theory (PET) was born of our unhappiness with policy process models that emphasized stability, rules, incremental adjustments, and gridlock whereas we saw policy change as oftentimes disjoint, episodic, and not always predictable."

PET builds on some micro foundations of human decision making, where cognitive and emotional architectures have been hypothesized to be the main source of humans' limited attention spans (Jones 1994, 2001). Human beings are disproportionate information processors who can process a limited number of information streams simultaneously (Jones 2001; Jones and Baumgartner 2005). These micro-level incapabilities interact with what Jones, Sulkin and Larsen (2003) call 'institutional friction', the transaction costs that are associated with decision making and that make policy changes more difficult (e.g., coalition governments). For instance, according to Jones and collaborators (2003), statutes and public budgets are subject to various operational procedures that inhibit drastic changes. As a consequence, individiual-level cognitive limitations along with 'institutional frictions' result in non- 
normal distributions of (e.g., leptokurtic) of policy changes (Jones, Sulkin and Larsen 2003; Mortensen 2005; Jones et al. 2009; Baumgartner et al. 2009; Baumgartner et al. 2017). Scholars testing the implications of PET found strong evidence for this framework in various contexts and contributed to the generalizability of it (see Baumgartner, Jones and Mortensen 2014).

One of the major consequences of humans' (and institutions') disproportionate information processing is that under- and over-reactions to policy issues often dominate the political process (Jones 2001; Jones and Baumgartner 2005). As summarized above, the proponents of behavioral models of issue attention argue that the two great sources of these under- and over-reactions to incoming information about societal issues are institutional settings and cognitive capacities (Jones, Sulkin and Larsen 2003; Jones et al. 2009; Baumgartner et al. 2009). Although we know a great deal about the institutional factors (Baumgartner and Jones 1993; Baumgartner, Jones and Mortensen 2014), however, the role that cognitive capacities play in human choice is relatively underexplored (Brouard 2013; Shaffer 2017; Thomas 2017). More strikingly, studies building on the punctuated equilibrium framework have made important assumptions about human decision making without exploring the potential determinants of individual-level disproportionate information processing. As Shaffer $(2017,89)$ puts it, this is not trivial, "since many of the existing explanations for aggregate-level policymaking patterns are based on individual-level cognitive phenomena, providing evidence for the presence of these effects is a critical analytic step."

In this dissertation, my broader objective is to contribute to the growing body of research that explores the cognitive and attentional underpinnings of the oft-cited information processing patterns. We know that "the bursty nature of human behavior is a consequence of a decision-based queuing process: when individuals execute tasks based on some perceived priority, the timing of the tasks will be heavy tailed, 
with most tasks being rapidly executed, whereas a few experience very long waiting times" (208). What we do not know is whether this decision-based queuing process varies across the cognitive styles of individuals. A systematic analysis that explores the variation in attention allocation among human decision makers will advance our understanding of various micro (e.g., voting behavior) and macro (e.g., legislation) political phenomena. If particular groups of people differ from one another in attention spans, this should have political implications for the institutions human decision makers inhabit.

Scholars following this body of research build on the assumptions about the information processing capacity human decision makers (Baumgartner, Jones and Mortensen 2014 for an overview). Although these micro foundations are widely accepted, no attempt has been made to explore whether individual-level information processing and attention allocation patterns vary across individual traits. This comes as a sizable surprise, as large strands of research in cognitive sciences suggest considerable differences in modes of thought and cognitive styles. For instance, George Lakoff (2008), a prominent cognitive scientist, argues that progressive and conservative modes of thought are dominated by 'politics of empathy' (e.g., social justice) and 'politics of authority' (e.g., hierarchy, respect). Similarly, a group of political scientist who introduced the study of 'political neuroscience' underscore the importance of individual-level differences (Smith et al. 2012; Hatemi and McDermott 2012; Schreiber et al. 2013; Jost et al. 2014). These scholars found that progressives and conservatives engage in different cognitive processes when they think about various social and political phenomena (e.g., risk, threat, disgust). Another line of research has shown that gender (or biological sex) is just another dimension based on which we can explore individual-level differences in cognitive styles. According to this, women show more concern for societal issues (i.e., empathy, theory of mind) and process incoming information more comprehensively (Baron-Cohen 2002; Zahn-Waxler et al. 
1992; Baron-Cohen et al. 2005; Brosnan et al. 2014; Christov-Moore et al. 2014). If there are significant individual-level differences in human information processing, then the sociodemographic composition of institutions (political parties, legislatures, bureaucratic agencies etc.) may have important consequences for issue attention and agenda diversity.

In this project, I make the first attempt to explore the determinants of individuallevel issue carrying capacity by combining cognitive and issue-based approaches in the study of issue attention and information processing. I argue that although macrolevel theories of political agenda-setting do a good job of explaining the dynamics of agenda diversity over time, there is still some room for micro-level explanations (e.g., human choice, information processing capacity of individuals). The literature on cognitive psychology shows that there are significant gender differences in the way human beings process information about societal and political issues. According to this line of research, females are 'comprehensive information processors' whose cognitive skills draw more heavily on 'empathizing' (Baron-Cohen 2002, 2004). I theorize that this superior empathizing skills should lead females to detect higher number of policy problems. In other words, females' lower cognitive threshold of urgency for societal problems should result in higher levels of problem identification. Accordingly, I posit that superior empathizing skills, coupled with superior emotional memory and higher perception of risk, should lead female decision makers (political elite or voters) to pay attention to a wider range of societal issues.

This dissertation makes an important contribution to the study of policy process and political behavior. First, studies adopting the punctuated equilibrium framework have implicitly assumed a unified pattern for human decision makers that inhabit organizations: irregularities in attention allocation patterns among individual decision makers should result in under- and over-reaction to the incoming information. I provide nuance to this framework by documenting substantial evidence that there are 
significant variations among individuals in their attention spans and that women, on average, are less likely to display disproportionate information processing. This finding implies that institutional attention allocation may not follow a uniform pattern, where the composition of men and women in organizations (e.g., legislatures) may shape issue attention.

Secondly, this dissertation contributes to the growing body of research that examines the linkages between identity and issue attention. Although previous scholarship has shown that there are various gender differences in policy priorities, it has explored gender differences in either a single policy issue or a limited number of issues. This dissertation undertakes the most comprehensive test of the hypothesized gender differences in policy priorities and shows that such differences are much stronger than previosuly thought. More importantly, no attempt has been made to explore whether the scope of societal issues with which human decision makers are involved varies by gender, which has important implications for voting behavior and democratic satisfaction.

Before I go any further, it is important to clarify the key concepts utilized in this study. I define issue-carrying capacity as the scope of societal issues with which human decision makers, whether representatives or voters, are involved. For instance, in the American National Election Studies (ANES) survey that was conducted between 12 September and 7 November in 1960, a male respondent listed only the foreign policy while a female respondent listed the foreign policy, education policy, and civil liberties as the most important problems facing their country. In a Gallup survey conducted in July 2013, a male respondent listed only the budget deficit while a female respondent listed corruption, unemployment and housing as the most important problems. In another example, an Austrian male respondent was asked in 1999 about the most important problems facing his country and listed agriculture and immigration while a female respondent listed immigration, education, health, and corruption as the most 
important problems. In all three examples, the female respondents were considered to have a higher issue-carrying capacity. ${ }^{1}$

\subsection{Outline}

The following chapter introduces my theoretical expectations drawn from political science, cognitive and behavioral psychology research. The literature on sex differences in cognitive styles persuasively shows that women are more sensitive to the problems facing others (Baron-Cohen 2002, 2004, 2010) and they process information and social cues more comprehensively (Meyers-Levy 1989; Meyers-Levy and Sternthal 1991; Meyers-Levy and Maheswaran 1991). One of the implications of these differing cognitive styles for the processing of information about the external environment (such as societal problems) concerns the range of issues that men and women choose to attend to. Given that complex systems such as societies face numerous problems simultaneously (Jones 2001), those who have lower sensitivity threshold for problems facing their society should be more likely to 'detect' those problems brought by various information streams. That is, among the individuals who are exposed to similar streams of incoming information (e.g., news stories, constituency demands), women should prioritize a larger number of issues due to well-known sex differences documented by various subfields of psychology. I build on these insights and develop a theory of gender differences in issue-carrying capacity.

Chapter 3 deals with two fundamental questions that constitute the foundation of my theoretical expectations. As I will discuss in more detail in Chapter 2, neuroscientists have documented evidence that women differ from men in cognitive and neural structures that shape perceptions and judgements of social and political stimuli. Fol-

\footnotetext{
${ }^{1}$ Measuring issue-carrying capacity requires a different strategy while working with political elites, as representatives can make multiple speeches on a given issue. I explain the empirical strategy utilized for measuring the issue-carrying capacity of legislators in Chapter 2.
} 
lowing this body of research, one can argue that women should differ systematically from men in attention to issues related to care, harm and empowerment such as war casualties, education, and social assistance. Indeed, a plethora of research has shown that there are significant gender differences toward several policy issues, though the roots of such differences remain to be answered. While women have been hypothesized to pay more attention to issues that are traditionally known as 'feminine', empirical research investigating such differences in 'feminine-masculine' issues was limited in scope. I undertake the most comprehensive study to date to investigate gender differences in policy preferences. Empirical results show that gender differences in policy priorities go beyond the 'feminine-masculine' issues and that they are much stronger than previously thought. Additionally, since scholars have hypothesized that gender (or biological sex) differences in cognition and information processing are caused by neurobiological and social factors, one can argue that these differences should remain fairly stable over time. Results show that gender differences in most policy categories remained stable over time, a finding that calls for rethinking the oft repeated claim that gender differences in policy preferences are time- and context-driven. These results lend support to the hypothesis that women pay particular attention to issues related to care, harm and empowerment.

Chapter 4 presents the first empirical test of the proposed hypothesis, where I utilize public opinion data to test my theory of gender differences in issue-carrying capacity. I expect female respondents to attend to a broader range of societal issues facing their country. Utilizing the European Election Study (EES) surveys conducted in 12 European countries in $1999(\mathrm{~N}=13,549)$ and 94 nationally representative surveys conducted between 1960 and 2015 in the US (N=110,796), I test the hypothesized gender differences in information processing and issue-carrying capacity. Results based on a series of multilevel mixed-effects Poisson regressions show that women do indeed attend to a broader range of issues when asked about the most important problems 
facing their country, a finding that is insensitive to various alternative model specifications and robustness tests. These results also show the utility of drawing together the research on cognitive psychology and public opinion to explore the dynamics of issue attention at the individual and institutional levels.

Chapter 5 extends the empirical investigation undertaken in the previous chapter to gender differences in representatives' information processing and issue-carrying capacity. Since my theoretical expectations derive from the well-known sociopsychological factors that shape human information processing, gender differences in issue-carrying capacity should not be limited to voters. Utilizing original datasets that consist of over 18,000 parliamentary speeches and the biographies of over 1,100 members of parliament (MPs) who served in the Grand National Assembly of Turkey between 1999 and 2011, I explore sex-related differences in MPs' issue attention in the parliament. Drawing together the literatures on political agenda setting, gender studies and cognitive psychology, I argue that women's lower cognitive threshold of urgency for societal issues leads them to pay attention to a wider variety of issues facing society and find strong support for this hypothesis.

Chapter 6 concludes by summarizing the major findings of my dissertation and outlining an agenda for future research. I consider potential implications of these findings and discuss the need to find new methods to measure issue-carrying capacity. As an example, I argue that increasing women representation in decision making institutions (e.g., legislatures) might lead to a more diverse agenda at the institutional level. In a recent study, Greene and O'Brien (2016) have documented empirical evidence that increasing women representation in legislatures leads to a larger scope of issues represented on the manifesto. As Baumgartner and Jones (2015) argues, more diverse streams of information may help political elites to reveal different aspects of societal problems and change policies accordingly. In Chapter 6 I will discuss these implications in more detail. 


\section{Chapter 2}

\section{An Attentional Theory of Issue-Carrying Capacity}

In this chapter, I explore the cognitive foundations of issue-carrying capacity among human decision-makers. I first discuss the well-documented patterns of attention allocation and information processing among individuals and the role these patterns play in various macro phenomena. Building on the bounded rationality framework and theories of human information processing (Newell and Simon 1972; Simon 1979; Jones 1994, 2001), I argue that while the characteristics that dominate human information processing (e.g., limited attention spans) are universal, the process of information processing should vary with individual characteristics. Bringing together cognitive and neuropsychology literature on gender with established research on policy agendas and issue attention to add an obvious, but not yet studied, dimension to our understanding of information processing in human decision making, I posit that neural and cognitive differences between females and males should result in differing levels of issue-carrying capacity. That is, female decision-makers should attend to a wider variety of issues when given the opportunity to express their opinions about the problems facing their country. 


\subsection{Information Processing and Cognitive Styles}

Bryan Jones $(2001,86)$ once famously wrote, "nowhere do comprehensive and bounded rationality differ more than in the treatment of information." Indeed, the proponents of comprehensive rationality (i.e., rational choice theorists) assumed that information processing results simply from exchanges of signals between senders and receivers, which are regulated by incentives (see Simon 1979). However, as Herbert Simon contends, information-processing is dominated by some 'invariant characteristics' of human problem-solving efforts: the information-processing system "operates almost entirely serially, one process at a time, rather than in parallel fashion. This seriality is reflected in the narrowness of its momentary focus of attention... [and] the inputs and outputs of these processes are held in a small short-term memory with a capacity of only a few (between, say, four and seven) familiary symbols, or chunks" (Simon 1978, 273). The process of transforming the input streams into opinions is a product of attention, inattention, short- and long-term memory (Newell and Simon 1972; Jones 2001). Although there is little doubt that this process is universal, the ability to process the incoming information about the external environment should vary with individual characteristics.

The role of information processing in explaining macro political phenomena has been examined by previous scholarship (Jones 2001; Jones and Baumgartner 2005; Alexandrova et al. 2012; Baumgartner et al. 2017). Although these macro-level studies relied heavily on individual-level assumptions about human information processing (e.g., bounded rationality), little attempt has been made to explore the extent to which disproportionate information processing varies with socio-psychological characteristics. In Shaffer's $(2017,89)$ words, "since many of the existing explanations for aggregate-level policymaking patterns are based on individual-level cognitive phenomena, providing evidence for the presence of these effects is a critical analytic step." As disproportionate information processors, Baumgartner and Jones $(2015,46)$ astutely 
point out, "we underattend to issues below some cognitive threshold of urgency and then later we react in surprised alarm to something that may have been there for quite some time, but to which we were not paying sufficient attention," which they called basic characteristics of human decision making, rather than 'anomalies'. The necessity of dealing with a large number of issues simultaneously results in underand over-attention to particular issues (Jones and Baumgartner 2005). In Barabasi's (2005) words, "the bursty nature of human behavior is a consequence of a decisionbased queuing process: when individuals execute tasks based on some perceived priority, the timing of the tasks will be heavy tailed, with most tasks being rapidly executed, whereas a few experience very long waiting times" (208). However, we have scant knowledge of whether there is any variation among human beings in their attention allocation patterns. If so, what are the consequences of it? As an attempt to fill this theoretical gap, I draw together research in various fields of psychology and political behavior, and argue that female-male differences in cognitive styles lead to differing levels of information processing patterns between men and women. In particular, I posit that if there are systematic female-male differences in individuals' cognitive threshold of urgency for societal problems, then these differences should have observable implications for political behavior.

"The cognitive or thinking process begins with the ability to sense changes in the environment and to make meaning out of the sensory stimuli constantly impinging on us" (Halpern 2013, 104). However, this process does not exist in a vacuum; a great deal of variation in cognitive styles, "people's characteristic and typically preferred modes of processing information" (Sternberg and Grigorenko 1997, 700), has been documented by a large corpus of work in cognitive and behavioral psychology (Witkin and Ash 1948; McClure 2000; Kozhevnikov 2007; Schulte-Rüther et al. 2008). One source of difference in cognitive styles has been attributed to sex-related differences and gender roles. According to this line of research, females differ significantly from 
men in the way they process information about external environment (Baron-Cohen 2002, 2004; Baron-Cohen et al. 2005). More specifically, female subjects have been shown to display superior social understanding and empathy for others (Happe 1995; Baron-Cohen 2002; Schulte-Rüther et al. 2008), more reaction to unpleasant materials (Bradley et al. 2001; Soroka et al. 2016), and produce memories with greater emotional intensity in response to cues (Canli et al. 2002). The implications of these differing cognitive styles, however, have received scant academic attention in public opinion research.

Drawing upon previous scholarship on female-male differences in cognitive styles in general, emotional memory and empathic response to external stimuli in particular, I argue that women's lower sensitivity threshold of urgency for societal problems and their advantage in encoding and recalling information generated through empathic response should have observable implications for political behavior. Specifically, I argue that such differences should lead female respondents to list a larger number of societal issues when asked about the most important problems facing their country.

\subsection{Gender Differences in Cognitive Styles and At- tention}

\subsubsection{Social Roles, Norms and Values}

Various explanations have been proposed as to how and why females tend to differ from their male counterparts in issue attention, information processing and cognitive styles. The first of these explanations concerns the role of socialization. Sociologists and social psychologists have long argued that differing socializations and experiences are the driving force behind gender differences in distinct values and perspectives (Chodorow 1978; Ruddick 1980; Beutel and Marini 1995). According to this view, 
gender role beliefs interact with division of labor to produce sex differences in cognition and attitudes (Parsons and Bales 1955; Eagly and Wood 2011). In an early study, Bakan (1966) classified differences in human values and traits along the dimension of agentic-communal qualities, where women are thought to have strong communal qualities such as selflessness and concern with others while men are more assertive and competitive (see also Parsons and Bales 1955; Eagly 2009). In a forceful contribution, Conover (1988) examined gender differences in basic value orientations and found that women have more positive feelings that men do toward the disadvantaged sections in the society, which the author suggests can explain broader gender differences in political attitudes. Following this line of reasoning, meta-analytic reviews showed that there are significant female-male differences in aggressive and helping behavior, and these differences are consistent with the predictions of the social-role theory of gender (Eagly and Steffen 1986; Eagly and Crowley 1986). In particular, Eagly and Crowley (1986) document that female helping behavior is more likely to be associated with concern for others. These differences in gender roles and personalities are so striking that women in leadership positions who are perceived to disconfirm the well-known gender stereotypes (i.e., 'communal' vs. 'agentic') in the workplace suffer from what social psychologists call the 'backlash effect' (Rudman 1998; Heilman 2001; Lyness and Heilman 2006; Rudman and Phelan 2008).

Most recently, Wood and Eagly (2012) extended the scope of the social-role theory by including biological processes that interact with traditional gender roles to produce sex differences and similarities. As it stands, the implications drawn from the 'biosocial-role' theory are consistent with the empirical evidence that women differ from men in psychological dispositions. The figure below describes the sociopsychological processes suggested by the 'biosocial-role' theory. According to this, evolutionary pressures that resulted from biological differences have led to division of labor among individuals, which in turn created gender role beliefs. These role beliefs further bol- 
Figure 2.1: Biosocial Construction Model

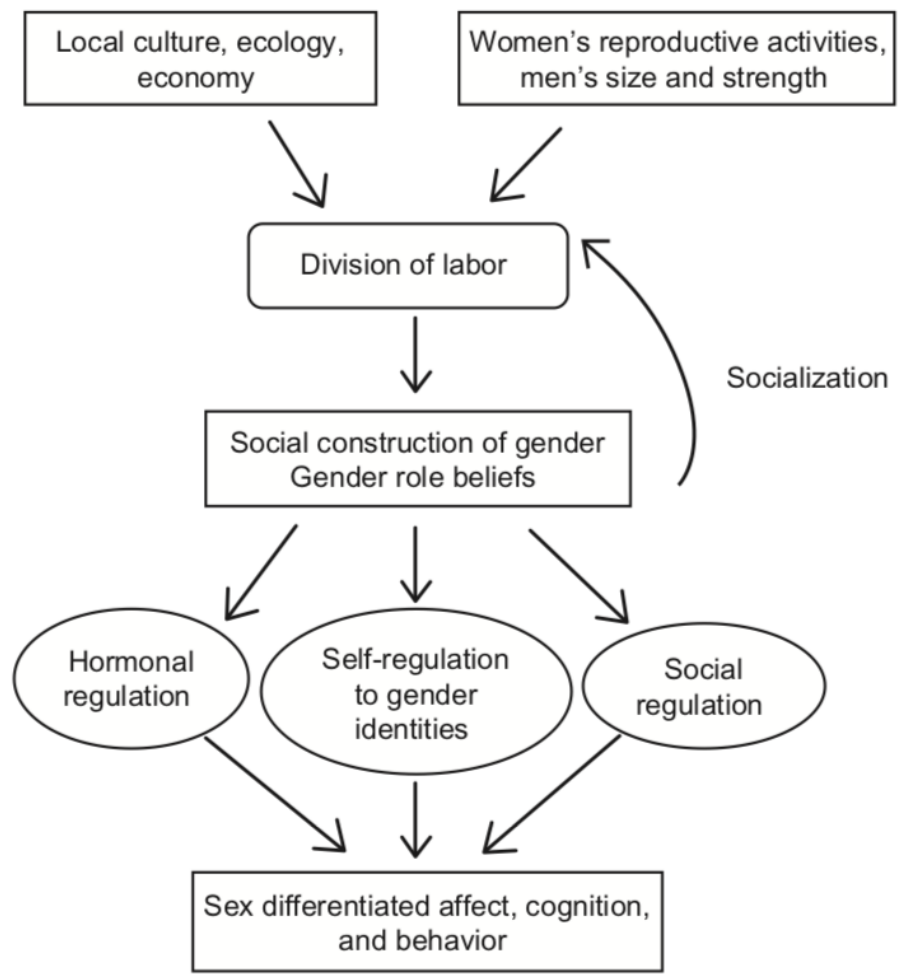

Source: Wood and Eagly (2012)

stered the division of labor within the society and interacted with biological and social regulation to pave the way for gender differences in attitudes and behaviors. In Wood and Eagly's (2012, 57-58) words:

"Within societies, the division of labor sets in place a cascade of psychological and social processes. These processes, in turn, stabilize the current division by making it seem sensibly tailored to the attributes of women and men. Thus, people infer the traits of men and women from observing their behaviors, and they generally regard these traits as intrinsic to each sex. For example, if women care for children, they are thought to be nurturing and caring, and if men fight wars, they are thought to be tough and brave. Such gender role beliefs, shared within a society, promote socialization practices that encourage children to gain the skills, traits, 
and preferences that support their society's division of labor. Gender roles encourage most adults to conform to these shared beliefs by confirming others' expectations and by internalizing them as personal standards for their behavior. In addition, biological processes such as hormonal activation support gender role behaviors. By this confluence of biosocial processes, individuals within a society dynamically construct gender in patterns that are tailored to their time, culture, and situation."

\subsubsection{Brain, Cognition and Emotional Memory}

Another line of research speaking to sex differences in cognitive styles holds that female advantage in social understanding and processing of emotional cues may be explained in part by brain activities (see Canli et al. 2002 for an overview). One view suggests that females tend to display more intense reactions to emotional events, which in turn leads to an effective encoding of signals received from those events (Fujita et al. 1991). Testing this theory in an experimental setting, the authors showed that women were significantly more likely than men to recall both positive and negative memories. In line with this view, other studies showed that women not only respond more strongly to negative emotional stimuli (e.g., negative news content) than men (Stevens and Hamann 2012; Soroka et al. 2016), they also outperform men in various memory tasks such as name associations, face recognition, object location, images, and incidental memories, among others (Harshman and Paivio 1987; West et al. 1992). Seidlitz and Diener's study $(1998,269)$ of sex differences in recall revealed that women are more likely recall both negative, positive and neutral life events, which led the authors to conclude that "the detail with which the life events were encoded in memory may have contributed to women's superior recall." Although scholars have yet to reach a consensus over the potential reasons for such differences, an emerging view is that both hormones and sex-typed personality traits (masculinity/femininity) 
may be responsible for these differences (Hamann and Canli 2004).

A growing body of neuroimaging studies have examined brain activity while men and women were exposed to negative and positive emotional stimuli (Hamann 2005). These studies have identified various sex differences in the amygdala (Cahill et al. 2001), a structure in the temporal lobe that is responsible for a variety of physiological and behavioral responses given to incoming information (Davis and Whalen 2001). It is also known that the amygdala is involved in long-term memory associated with emotionally arousing events (Cahill 2000). Cahill and collaborators (2001, 2004) have documented differing patterns in activity of the amygdala, such as hemispheric asymmetry, with respect to memory for emotionally arousing events in women and men (favoring women). As a result, it is likely that women not only respond more strongly to emotional stimuli, but also encode them by consciously accessible means (Canli et al. 2002).

Although the causal mechanism behind female-male differences in emotional memory is still open to debate, two implications flow from the argument that females are comprehensive information processors who rely heavily on social cues when forming opinions (Darley and Smith 1995, 43): Females may encode more information than males and/or elaborate available cues more extensively. Additionally, it has been argued that males selectively use highly available cues that are salient in a given context (Meyers-Levy and Sternthal 1991; Meyers-Levy and Maheswaran 1991). This may help explain why male representatives speak significantly more about "hard issues" (i.e., masculine issues) such as macroeconomics and finance (see Bäck, Debus and Müller 2014), which tend to be highly salient issues that produce more available cues.

Neuroscientist have shed further light on male-female differences in information processing, emphasizing that such differences should not be simply attributed to social environment as various neurobiological factors play major role in shaping sex differences in cognitive styles (see Savic 2010 for a review). Supporting this view, Hannagan 
et al. $(2014,107)$ analyze the political knowledge gap between men and women, and report that "the variation among women is being driven by additive genetic effects as opposed to environmental sources." One of the broader conclusions the authors reached is that additive genetic effects may help us better understand why women differ from men in processing social and political information. In fact, a large body of research in cognitive sciences has documented that there are considerable sex differences in the way human beings process incoming information surrounding them (e.g., Maccoby and Jacklin 1974; Halpern 1997, 2013; Herlitz, Nilsson and Bäckman 1997; Halpern and LaMay 2000; Block, Hancock and Zakay 2000), though it is commonly accepted that there is no reliable evidence suggesting one sex is smarter than the other (Hyde 2005; Halpern 2013; Dykiert et al. 2009). Specifically, studies indicate that women perform better than men on episodic memory tasks (Herlitz, Nilsson and Bäckman 1997; Block, Hancock and Zakay 2000), verbal fluency and social sensitivity (Baron-Cohen et al. 2005), while being outperformed by males in spatial cognition and computational fluency (Halpern 2013). In one of the largest functional brain imaging studies to date, Amen and collaborators (2017) found that the prefrontal cortex, part of the brain that is associated with such traits as self-awareness, appropriate concern, empathy and collaboration, is significantly more active in women compared to men. Indeed, this body of research finds that females' advantage in empathy and general social interest appears to be consistent even in infants and children (Christov-Moore et al. 2014) and that women outperform men in most emotion recognition tasks (Donges et al. 2012; Thompson and Voyer 2014).

Psychologist Simon Baron-Cohen $(2002,2004)$ suggests that cognitive styles may be classified along the dimensions of 'empathizing' (the drive to identify mental states and emotions) and 'systemizing' (the drive to analyze or build systems). The empathizing-systemizing (E-S) theory proposes that there are significant differences between females and males in the degree to which they empathize and systemize. 
More specifically, while concern for fairness, distress of others, reciprocal relationships and various other empathizing abilities dominate the cognitive style of females, the male cognitive style is heavily dominated by systemizing abilities such as measurements, spatial navigation, and computation (Baron-Cohen 2002, 2004; Goldenfeld et al. 2005). Quite importantly, sex differences in empathy, fairness, sensitivity to social cues and emotions have been observed by studies involving subjects as young as one year old (Happe 1995; Baron-Cohen 2002), underscoring the genetic prenatal roots of such differences (Rushton et al. 1986; Geary 2005; DeSoto et al. 2007). Connellan and collaborators (2000) found that female infants spend significantly more time looking at a social object (i.g., human face), whereas male infants showed a stronger interest in physical-mechanical object. Analyzing the development of empathy and altruism in twin pairs, scholars reported significantly higher empathy and altruism scores for girls and women than boys and men (Rushton et al. 1986; Zahn-Waxler et al. 1992). Delving further into the E-S theory, Brosnan et al. (2014) found that there are strong correlations between empathizing with intuition and systemizing with deliberation and that documented significant sex differences in empathizing (favoring women) and systemizing (favoring men). Although the questions as to what causes these differences and whether cultural and other environmental factors play any role in shaping them are still open to debate, the proposed theory of females' superior social understanding has found strong support from a large body of research in various subfields of psychology (Lawson et al. 2004; Wheelwright et al. 2006; Billington et al. 2007; Focquaert et al. 2007; Schulte-Rüther et al. 2008; Manson and Winterbottom 2012).

The ability to understand and share another's feelings and emotions has been widely accepted as a biological phenomenon that evolves early in human development (Preston and De Waal 2002; Decety and Jackson 2004; Korkmaz 2011; Miller 2009). Two different concepts, empathy and Theory of Mind (ToM), have been intro- 
duced to capture the processes through which human beings understand the internal states of others. Although "empathy and ToM are different processes that engage partially shared areas of the brain" (Ibanez et al. 2013, 616), ToM is thought to be the cognitive component of empathy (Baron-Cohen 2010). Analyzing the link between empathy and sex as the predictor of ToM, Ibanez and collaborators (2013) found that sex has a direct and indirect effect (mediated by empathy) on levels of ToM, confirming the well-established finding that there are significant sex-related differences in empathy and ToM favoring females (see also Calero et al. 2013). A study published in Nature showed that empathy-related activation in brain was significantly more likely to be reduced in males when subjects empathized with the pain of persons they disliked (Singer et al. 2006). Stated differently, empathic responses in men, but not in women, may be highly contingent on the perceived fairness of others. As an example to put this in perspective, among those who perceive the needy as 'undeserving poor' male decision-makers, compared with females, may be less likely to consider poverty as the most important problem.

In a recent study, political scientist Stuart Soroka and collaborators (2016) use physiological measures to examine whether women differ from men in responding to television news content. Their results suggest that women are more attentive than men to negative news content, as evidenced by the decreasing heart rate when the subjects were exposed to negative news. An extensive meta-analysis of neuroimaging studies has revealed that there is a growing consensus on sex differences in brain activation during emotion processing: women respond more strongly to negative emotional stimuli than men (Stevens and Hamann 2012). Additionally, compared with men, women perceive higher risks from crime, violence, poverty, stress, and environmental and health-related hazards (Gwartney-Gibbs et al. 1991; Slovic et al. 1993; Flynn, Slovic and Mertz 1994; Barke et al. 1997). Following Meyers-Levy's (1989) selectivity hypothesis, one strand of research in consumer psychology examined sex- 
related differences in attention and found that females adopt a more comprehensive approach to information processing (Darley and Smith 1995; McGivern et al. 1997). McGivern and collaborators $(1997,324)$ summarized the central argument developed by this line of research as follows:

"Males tend to employ various heuristic devices to organize and filter information as it is processed. These serve as scaffolding for more detailed processing and are often characterized by their personal or self-related salience. In contrast, females process information more comprehensively. Their information processing is likely to include a balance between information pertinent to the self and to others. Thus, females rely less than males on heuristic devices that organize information in a self-oriented hierarchical processing style."

Increasing number of psychologists attribute sex differences in empathizing and systemizing to sexual selection in human evolution (Geary 1998; Taylor et al. 2000). A widely accepted view emerged from this strand of research in evolutionary psychology is that females and males have had different set of social pressures since the premodern times (Taylor et al. 2000). Specifically, scholars argue that females' tendency to migrate to another group (i.e., philopatry) led them to invest heavily in social support networks with non-kin and develop various social skills such as reciprocal altruism that help them adapt to changing social ecology (Geary 2006; Geary and Flinn 2002). In a striking contrast, males' tendency to form kin-based networks to compete for control of resources are thought to have defined males' social styles (Geary 1998). Numerous studies documented findings consistent with this view: "Compared with girls, boys ... are less likely to acknowledge another's viewpoint, are more focused on dominance and status, are more likely to be directly competitive, are more tolerant of inequalities in relationships and interpersonal conflict, and are less attentive to the emotional states of conversation partners" (Byrd-Craven and Geary 2007, 16). 


\subsubsection{Information Processing in Political Behavior Research}

The scope of societal issues with which human decision makers are involved has attracted scholarly attention in political behavior research as well. At the individual level, one line of research emphasized the importance of memory in opinion formation and expression. Indeed, as cognitive scientists showed, information processing cannot be thought independent of human memory processes, which are "divided into the structures of LTM [long-term memory] and WM [working memory] and most often represented as an associative network" (Taber 2003, 446). In the context of public opinion, scholars argue that answering attitude questions requires the retrieval of previously formed opinions (or associational cues, see Anderson and Bower 2014) from long-term memory, a process that is likely to be based on a "sampling process that over-represents the most accessible beliefs or situational cues" (Tourangeau and Rasinski 1988, 300). Zaller and Feldman $(1992,586)$ put forward a similar argument, stating that individuals average across the most salient considerations, the accessibility of which depends on a 'stochastic sampling process'. Therefore, opinions about the most important problems facing the country may be a product of empathic responses to societal problems and the degree to which such responses are encoded by consciously accessible means. Taken together, one of the implications of the findings that suggest superior associative and emotional memory for women is that (Hedges and Nowell 1995), in Zaller's terms $(1992,51)$, although women and men may not differ in 'receiving' new information they do differ in the way they 'accept' and 'sample' that information when asked about the most important problems facing their country. As an example, based on the empirical evidence discussed above, one can argue that women news consumers, as compared to men, not only show more concern about the poverty-related news stories they read, they also encode that news story in a more accessible way, increasing the likelihood of considering poverty as an important problem facing their country when asked about their opinions. 
Although these arguments have not yet been tested at the individual-level, the assumptions drawn from individual-level cognitive patterns are adopted in aggregatelevel analyses. Scholars examine public agenda diversity, which I define as the aggregate level issue-carrying capacity, showed substantial evidence it varies by sociodemographic traits (Zaller 1992; McCombs and Zhu 1995; Mondak and Halperin 2008). Although the public agenda generally includes a small number of issues at a time (Shaw and McCombs 1977; Zhu 1992), this line of research posits that there are significant variations in agenda diversity among individuals. Such factors as political interest and political sophistication have been hypothesized to be powerful predictors of cognitive processes in agenda-setting research (Fiske et al. 1990; Krosnick and Milburn 1990; Zaller 1990). Allen and Izcaray (1988) found that higher socioeconomic status and news consumption are positively associated with agenda diversity. In line with this, studies also show that education is positively and age is negatively associated with agenda diversity (McCombs and Zhu 1995; Peter and De Vreese 2003). While sex has not yet been theorized as a predictor of agenda diversity, there is strong evidence in the literatures on cognitive and neuropsychology that women differ significantly from men in information processing, attention and memory (Canli et al. 2002; Hamann and Canli 2004). In fact, in an exploratory study of agenda diversity in four European countries scholars included the gender of respondents for the first time in their empirical models and found that female respondents attend to a wider range of issues (Peter and De Vreese 2003). This comes as a sizable surprise, as no theoretical explanations had been proposed in regards to the effect of gender in previous scholarship. While the authors did not address any potential explanation for this finding, they emphasize that the effect of gender on agenda diversity "should be investigated in more detail in further analyses" (58). 


\subsubsection{Hypotheses and Empirical Approach}

All in all, a plethora of research from different disciplines has shown that there are significant gender (or biological sex) differences in human information processing, and that females' information processing rely more heavily on social cues retrieved from the external environment. The present study draws upon various strands of research in political science and psychology to argue that women differ from men in issuecarrying capacity. Specifically, I argue that women's advantage in sensing changes in the environment and lower cognitive threshold of urgency for societal issues should result in differing scopes of societal issues with which females and males are involved. With higher potential for empathic response to societal issues, higher risk perceptions and enhanced capacity of encoding emotional stimuli, women may rely more heavily on external cues and issue frames when forming opinions about societal problems. Thus, I argue that in an information-rich world with abundant information channels (Jones 2001; Baumgartner and Jones 2015), women should be, ceteris paribus, influenced more by incoming societal cues and accordingly attend to a larger number of issues.Stated differently, women should prioritize a larger number of issues than their male counterparts as they tend to show more concern for societal issues. As disscussed in the previous sections, research on gender differences in psychophysiological characteristics and empathizing skills have have suggested that there are good reasons for these distinct patterns in issue attention.

Since my hypothesis draws heavily on assumptions that are expected to be universal (see Simon 1978), female-male differences in issue-carrying capacity should be observable among both the public and political elites. Empirical research conducting surveys with representatives and measuring their threat sensitivity using standard psychophysiological measures found that the biases that typically characterize human decision making are observable among political elites as well (Arceneaux, Dunaway and Soroka 2018; Sheffer et al. 2018). Therefore, if there are sex differences in issue- 
carrying capacity, the implications of such differences should not be different for the public and political elites.

My empirical approach for testing this hypothesis on two samples, the public and political elites, is not identical. For one thing, measuring issue-carrying capacity with public opinion surveys and legislative activities require different empirical strategies to explore the link between gender and issue diversity. In particular, while a simple count of the number of 'most important problem' responses would suffice for an analysis of issue-carrying capacity among the public, representatives typically find the chance to speak about each policy issue more than once. For instance, a legislator who considers education as the most important problem facing society may choose to make 10 speeches about this topic during her term of service, while still paying some attention to other societal issues. Therefore, counting the number of legislative speeches to examine issue-carrying capacity would be misleading. For this reason, I join the growing body of research that utilizes Shannon's H (entropy) index ${ }^{1}$ to measure the diversity of legislative activities (see Boydstun, Bevan and Thomas 2014). Since, unlike survey respondents, legislators have a much longer time to signal interest in their preferred policy issues, I use the concept 'entropic agenda', rather than issuecarrying capacity. ${ }^{2}$ Entropic agenda is a more suitable concept to measure the scope of issues legislators choose to focus on, as issue-carrying capacity might mistakenly lead readers to think of legislators with more speeches as 'high issue-carrying capacity' individuals. However, a legislator should be considered as having 'low issue-carrying capacity' if she speaks only about a single issue, even if she makes dozens of speeches about the given issue.

\footnotetext{
${ }^{1}$ This measure is the sum of probabilities of the different possible issue categories for each legislators, which will be described in more detail in the chapters that follow.

${ }^{2}$ These two measures, entropic agenda and issue-carrying capacity, are highly correlated. Hypotetically, a respondent who answers six MIP questions will receive a score of 1.79 , while a respondent with two answers (out of six) will receive a score of 0.69. In other words, higher issue-carrying capacity (i.e., the number of MIP question one answers) translates into a high entropic agenda score (i.e., the sum of probabilities of the different possible issue categories). Although different in nature, both concepts measure the capacity of attending to a wider range of issues.
} 
Table 2.1: A Hypothetical Distribution of Legislative Speeches and Diversity Scores by Legislators

\begin{tabular}{lccccc}
\hline \hline & Person 1 & Person 2 & Person 3 & Person 4 & Person 5 \\
\hline Topic 1 & 2 & 4 & 5 & 8 & 10 \\
Topic 2 & 2 & 4 & 5 & 2 & 0 \\
Topic 3 & 2 & 2 & 0 & 0 & 0 \\
Topic 4 & 2 & 0 & 0 & 0 & 0 \\
Topic 5 & 2 & 0 & 0 & 0 & 0 \\
Topic 6 & 0 & 0 & 0 & 0 & 0 \\
Issue Diversity Score & $\mathbf{1 . 6 1}$ & $\mathbf{1 . 0 5}$ & $\mathbf{0 . 6 9}$ & $\mathbf{0 . 5 0}$ & $\mathbf{0}$ \\
\hline \hline
\end{tabular}

Table 2.1 provides a hypothetical distribution of legislative speeches and the diversity scores associated with each legislator. Note that each legislator makes a total of 10 speeches about six hypothetical policy issues, though the distribution of speeches across topics varies by legislators. As seen in the figure, Person 1 makes two speeches about the first five policy issues and has a diversity score of 1.61. Person 2 receives a diversity score of 1.05, as she focuses more on Topic 1, 2 and 3 while ignoring other issue categories. Person 4 and 5 are the most concentrated representatives, devoting specialized attention to Topic 1 and 2, and receive very low diversity score. Following the discussion above, I summarize my hypotheses as follows:

Hypothesis 1: Female respondents, compared with their male counterparts, should list a higher number of issues when asked about the most important problems facing their country.

Hypothesis 2: Female legislators, compared with their male counterparts, should have a more entropic agenda (attending to a wider variety of issues) in the parliament.

In Chapter 3, I undertake an exploratory analysis to examine the extent to which women differ from men in policy priorities. Extant research has shown that women 
are more likely to focus on 'feminine' issues such as education and health, while men pay particular attention to 'masculine' issues such as homeland security and the economy. Empirical analyses provided in Chapter 3 lend strong support to the previously hypothesized linkages between gender and issue stereotypes. I argue that women's tendency to pay more attention to issues related to care, harm and empowerment (e.g., education, health, welfare etc.) is consistent with the differences in cognition and emotional information processing discussed above.

\subsection{Do Women Show More Concern for Societal Issues?}

Various strands of research in social, cognitive and neuropsychology have documented that there are good reasons to expect females to show more concern for societal issues. According to social psychologists, differing socializations and experiences drawn from traditional divisions of labor led women to develop distinct values and perspectives (Chodorow 1978; Ruddick 1980; Eagly and Crowley 1986; Beutel and Marini 1995; Eagly and Wood 2011). As a result of these socializations, the argument goes, women developed 'communal' qualities such as helping behavior and concern with others while men developed 'agentic' qualities such as competition and leadership (Bakan 1966). As I will delve further into these studies in the paragraphs that follow, the notion that females outperform males in communal tasks (e.g., helping behavior) has received utmost attention from various fields of psychology and has been supported by both observational and experimental studies.

Since this is an observational study that deals with public opinion and legislative activity data, the compelling question is whether these proposed gender differences are observable in self-reported measures such as public opinion surveys. Before developing my theory, I utilize the most recent wave of the World Values Survey (2010-2014) to 
Figure 2.2: Gender Differences in Attention to Social Problems

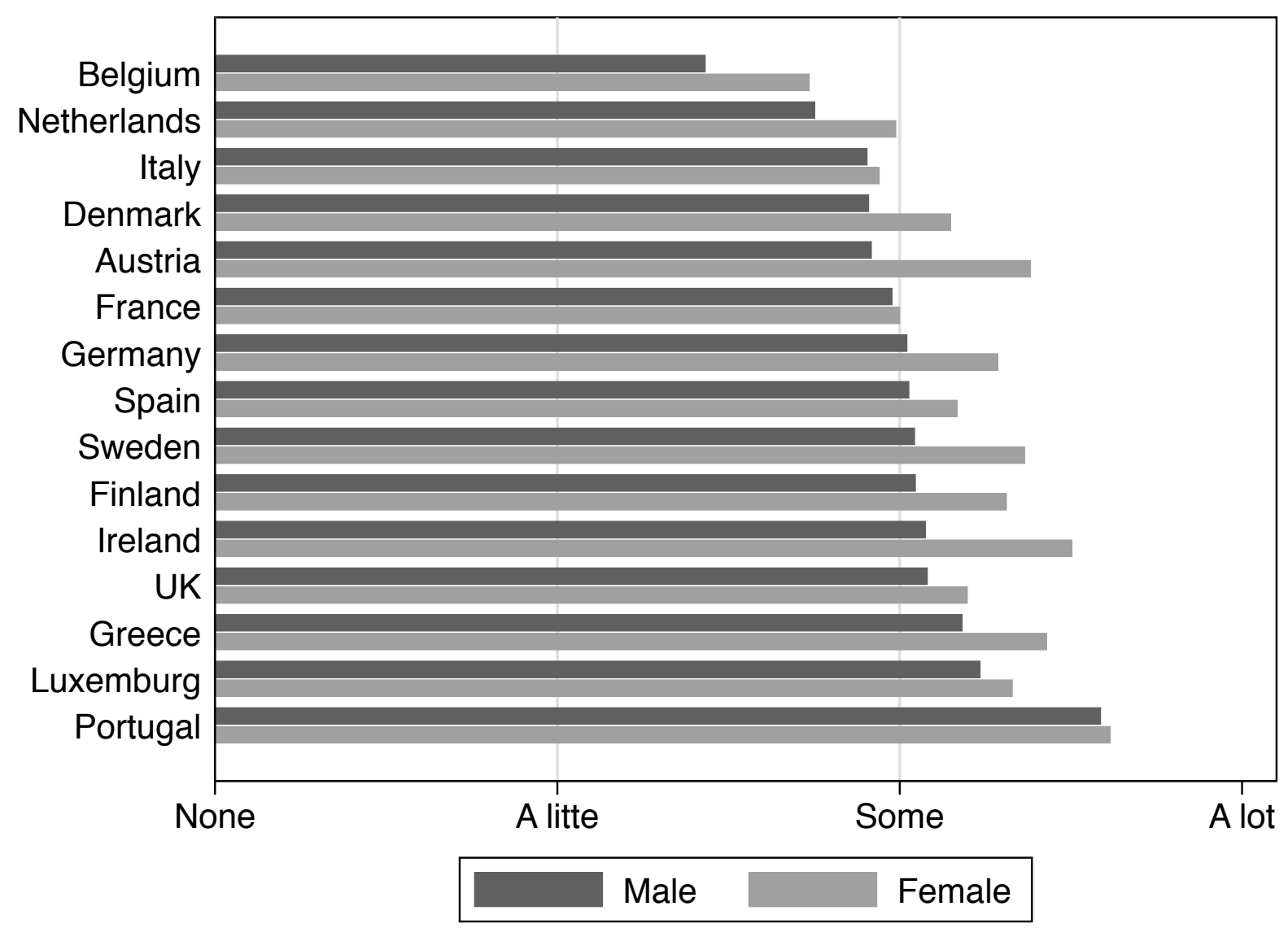

conduct a simple means-difference test in an attempt to explore the gender differences in care for others. In this wave the respondents were asked to rate the following statement: 'it is important to help people living nearby, to care for their needs' (i.e., Schwartz's values). The results show that women are indeed more likely to selfidentify with the above statement $(p<0.05)$. Secondly, I capitalize on the European Election Study (EES) surveys conducted in 12 European countries in 1999, where the respondents were asked to rate their attention to social issues. Figure 2.2 shows the mean scores of attention to social issues by country, with largers numbers indicating more attention to social issues. The figure clearly shows that female respondents report higher levels of attention to societal issues in all 12 countries in Europe.

I further interrogate the data to explore whether gender differences in attention to 
societal issues are context-driven. Results based on a series of mean-comparison tests show that among respondents who reported high news consumption (i.e., 5 or more days a week), female respondents pay more attention to societal problems $(M=3.26)$ than their male counterparts $(M=3.05), p<0.0001$. Similarly, among respondents who are highly or somewhat interested in politics, female respondents pay more attention to societal problems $(M=3.38)$ than male respondents $(M=3.13), p<0.0001$. The difference in attention to societal problems between female and male respondents is highly significant also among rural (female, $M=3.12$; male, $M=2.97$ ), urban (female, $M=3.23$; male, $M=3.01$ ), conservative (female, $M=3.09$; male, $M=2.88$ ), and liberal (female, $M=3.20$; male, $M=3.09$ ) respondents. Although the size of this difference varies across socioeconomic and political characteristics, in all cases women are significantly different from men $(p<0.0001)$. Taken together, these findings lend support to oft-cited claim that women, compared with men, are more concerned with societal issues. 


\section{Chapter 3}

\section{Gender Differences in Policy Priorities}

A large body of research has explored gender differences in policy priorities in various contexts (Welch 1985; Shapiro and Mahajan 1986; Swers 1998; Bratton and Haynie 1999; Reingold 2000; Herek 2002; Gidengil et al. 2003; Poggione 2004; Leal 2005; Schwindt-Bayer 2006; Funk and Philips 2018). One of the received wisdoms that has emerged from this body of research is that women and men differ greatly in responses to various questions in opinion surveys (Shapiro and Mahajan 1986; Leal 2005), and they pursue distinct policy agendas when they are elected to office (Thomas and Welch 1991; Swers 1998, 2001; Bird 2005; Schwindt-Bayer 2006; Celis and Childs 2008; Bäck, Debus and Müller 2014). While some of the differences between men and women in political behavior may be context-driven (Ayata and Tutuncu 2008, Jacobs 2014; Funk 2015), consistent empirical evidence for gender differences in policy priorities has been documented by numerous studies. Yet, despite the wealth of research on the subject, the great majority of empirical research has examined gender differences in only a handful of policies such as defense spending and war (Conover and Sapiro 1993; Bendyna et al. 1996; Leal 2005), environment (Steger and Witt 1989; Stern et 
al. 1993), welfare (Saint-Germain 1989), crime and justice (Applegate et al. 2002), and family issues (Schwindt-Bayer 2006). Although limited in scope, a few exceptions have examined gender differences in a wider range of issues and found that women are more likely to pay attention to what scholars call "feminine", "soft" or "compassion" issues (Huddy and Terkildsen 1993; Eagly et al. 2004; Page and Shapiro 2010; Bäck, Debus and Müller 2014; Funk and Philips 2018).

In this chapter I aim to advance our understanding of whether gender differences go beyond "feminine/masculine issues" and whether such differences in policy priorities are time- and context-driven. This is important for two reasons. Firstly, if women pay particular attention to issues related to care, harm and empowerment such as housing, poverty, social assistance, civil liberties, then this may mean that women will consider these issues as the most important problems facing their country even if such issues are not salient at the time. In other words, although the economy and foreign policy attract much more national attention at a given time, women may still consider other issues as the most important problems. Secondly, it is important to answer whether such differences are not time- and context-driven. Put differently, if gender differences in attention to 'feminine' or 'compassion' issues vary significantly by time and context, this would significantly reduce the generalizability of the argument proposed in this dissertation.

Leveraging a recently introduced dataset that codes over 930,000 Americans' responses to the "most important problem" from 1939-2015 using the same coding schemes (Heffington et al. 2017), I undertake the most comprehensive test of gender differences in policy priorities. This new dataset allows me to compare Americans' answers to the open-ended most important problem questions that were asked by various survey organizations over the past 75 years. Results based on a series of logistic regressions show that women focus more on "feminine" issues and that they differ from men in twenty-five of the twenty-nine policy categories under investigation. Ad- 
ditional analyses reveal that these differences have remained fairly stable over time. These findings imply that gender differences in policy priorities are much stronger than previously thought.

\subsection{Selective Attention to Feminine-Masculine Is- sues}

Previously, I have shown that female decision makers, representatives and voters, differ from their male counterparts in their issue attention due to cognitive and biosocial dispositions. Although political science research has not yet paid systematic attention to differences in issue attention and the potential reasons behind such differences, studies in various subfields of psychology have shed light on this underexplored ques-

tion. For instance, political scientists argued that women focus more on what are known as 'compassion', 'soft' or 'feminine' issues without fully acknowledging the sociological, psychological and evolutionary underpinnings of this tendency (see Page and Shapiro 2010; Bäck, Debus and Müller 2014; Funk and Philips 2018). Disaggregating 'compassion' issues and exploring gender differences in these policy areas over time would prove useful in understanding whether gender differences are time- and context-driven. If they are not, I argue, this would be an important signal that the underlying factors that bring about distinct issue attention patterns may be a consequence of the well-documented differences in cognitive and psychological dispositions.

A growing body of research focuses particular attention on gender differences in various aspects of political behavior at the elite and public level. Gender differences in legislators' issue attention has arguably attracted more attention, as legislative attention has been implicitly assumed to have more important consequences for the policymaking process (Gilens and Page 2014). We have scant knowledge of the extent to which women differ men in issue attention at the public level; therefore, drawing 
inferences about gender differences in issue attention requires us to rely more heavily on the literature on gender differences in legislative attention.

There is a plethora of research from both developing and developed world suggesting gender-based differences in issue attention in legislatures (Werner 1968; Kirkpatrick 1974; Diamond 1977; Bratton and Ray 2002; Swers 2001; Childs 2004; Childs and Withey 2004; Schwindt-Bayer 2006; Kittilson 2008). More specifically, research on women legislators show that female legislators bring new policy issues to the legislative agenda (Swers 1998; Schwindt-Bayer 2006). Although women deputies have often been hypothesized to be more liberal on many issues (Reingold 2000; Welch 1985; Hill 1983), they do not differ systematically from their male counterparts in legislative attention to more liberal issues (Mezey 1978). Bäck, Debus and Müller (2014) show that female legislators are far less likely to make a speech about "hard" policy issues, which are in the domain of male legislators. Similarly, categorizing policy issues into "feminine" and "masculine" subjects, Funk and Philips (2018) document that women prioritize feminine policy issues over masculine issues in budgetary decisions. Schwindt-Bayer (2006) analyzes representatives' issue attention in Latin America and finds that female legislators place higher priority on women's issues and children/family concerns. In another study, Thomas (1991) finds that states with higher percentage of female representatives pass more priority bills about women issues, children and families. In short, this strand of research has documented considerable evidence that women and men pursue distinct policy agendas once they are elected to office (Thomas and Welch 1991; Dodson 2006; Reingold 2000; SchwindtBayer 2006).

Although it has attracted less attention than the gender differences in legislators' policy priorities, similar gender differences at the public level have been documented by extant research. Evidence from across the globe suggests that women tend to be more liberal (Rapoport 1990; Shapiro and Mahajan 1986; Inglehart and Norris 2000) 
and more egalitarian than men (Sidanius et al. 2000), and their political agenda focuses more on "compassion" issues that involve advancement and empowerment of the needy, poor, and socially disadvantaged citizens (Page and Shapiro 2010; 296). Also, this line of research suggests that women, compared with men, are significantly less supportive of military action in foreign policy (Holsti and Rosenau 1981; Fite et al. 1990; Eichenberg 2003), more supportive of crime prevention (Hurwitz and Smithey 1998), and show greater concern over war casualties (Bendyna et al. 1996). Studies also report that economic evaluations play a significantly larger role in men's voting choices compared to women (Welch and Hibbing 1992), a finding that may suggest the importance of non-economic factors shaping women's evaluations of the government.

As discussed in Chapter 2, a number of social psychologists introduced what they call the "biosocial constructionist account" of sex differences in values, norms and psychological dispositions (Wood and Eagly 2012). According to this view, shared beliefs about the traits of genders interact with division of labor to produce sex differences in behaviors and attitudes (Bakan 1966). More specifically, women tend to outperform men in helping behavior and express positive feelings toward the poor and needy (Eagly and Steffen 1986; Eagly and Crowley 1986; Conover 1988). Different strands of research in cognitive and neuropsychology examined sex differences in various aspects of information processing, cognition and social attitudes and found empirical evidence consistent with the proponents of the social-role theory. Classifying the cognitive styles of males and females along the dimensions of 'empathizing' and 'systemizing', clinical psychologist Baron-Cohen $(2002,2004)$ argues that females, more than males, show concern for fairness and distress of others, and value reciprocal relationships. In contrast, males, more than females, develop systemizing abilities such as spatial navigation and computation (Baron-Cohen 2002, 2004; Goldenfeld et al. 2005). Studies testing Baron-Cohen's empathizing-systemizing theory have doc- 
umented supporting evidence for gender differences in empathy and social concern (Ibanez et al. 2013, Calero et al. 2013; Brosnan et al. 2014). Similarly, scholars of neuroscience delved further into sex differences in information processing and suggested distinct cognitive styles for males and females based on various neuroimaging tests that examined brain activity (see Canli et al. 2002 for an overview). According to this, women differ from men in the processing of emotional and social cues in the environment and encode these cues by consciously accessible means (Cahill et al. 2001; Canli et al. 2002; Hamann and Canli 2004). Scholars have argued that such differences in social behaviors and priorities can be traced back to evolutionary adaptations that were a product of social pressures (Geary 1998; Taylor et al. 2000). All in all, various lines of research in both political science and psychology suggest that women and men should have distinct policy priorities and that these priorities may be classified along the dimensions of feminine-masculine issues, given women's higher potential for empathic response, and care for harm, social justice and empowerment. If women, compared with men, pay more attention to such issues, then women may attend to a wider variety of issues even when 'compassion' issues (e.g., education, housing, health etc.) are not highly salient in the media. In other words, although both female and male respondents may be concerned with highly salient issues such as the economy and foreign policy at times, female respondents may be concerned with additional issues that do not attract much attention in the media, which naturally increases the female respondents' agenda size. That is, differences in feminine-masculine issues may not be perfectly symmetrical if female respondents are concerned with a higher number of issues. In statistical terms, the substantive impact of gender on differences in feminine issues might be larger than the effect of gender in masculine issues. Results presented below support this premise. 


\subsection{Data and Methods}

I utilized the Most Important Problem Dataset (MIPD), a dataset that contains Americans' responses to the 'most important problem' question from 686 public opinion surveys that were conducted by various organizations between 1939-2015 (Heffington et al. 2017). The MIPD codes the most important problem responses using three coding schemes, the Comparative Agendas Project (CAP), Singer and the Manifesto Research on Political Representation (MARPOR). Compared to the CAP and MARPOR, Singer coding scheme allows for a finer-grained analysis of policy priorities, as each entry is coded into a wider range of topics. For this reason, I created 29 binary dependent variables that measure whether the respondent listed the given policy issue as one of the most important problems facing society. ${ }^{1}$

Next, I collapsed these 29 policy categories to create two binary dependent variables, "feminine" and "masculine" political issues. Although these issues may vary considerably by context, it has become widely accepted that women pay more attention to issues related to harm, social justice, care, and empowerment due to sociopsychological and evolutionary dispositions (Bakan 1966; Geary 1998; Eagly and Wood 1999; Baron-Cohen 2002, 2004). Following the insights produced by gender and trait stereotyping research (Shapiro and Mahajan 1986; Huddy and Terkildsen 1993; Fox and Oxley 2003; Schwindt-Bayer 2006; Meeks 2012; Bäck, Debus and Müller 2014; Funk and Philips 2018), I categorize "feminine" and "masculine" issues as follows: While answers related to education, poverty, health care, housing, civil liberties, environment, welfare, family issues, and morals and values are coded as "feminine" issues, issues related to defense, terrorism, budget deficit, riots, unemployment, agriculture, energy sources, foreign aid and foreign policy were coded as "masculine"

\footnotetext{
${ }^{1}$ For instance, the variable Education measures whether a respondent lists education in at least one MIP question. Note that I restrict my analysis to the surveys with three MIP questions, in which respondents are free to answer only one or two MIP questions. A value of one indicates the respondent listed education as either the first, second or third most important problem (or multiple times); I do not rank the MIP questions.
} 
policy issues. $^{2}$

I utilize two sets of independent variables. Variables related to demographics include gender, age (log), education, income level, region of residence (i.e., South or not), whereas political variables include party identification and the party affiliation of the president at the start of survey fieldwork. Additionally, year and survey organization fixed-effects are included in the models. The descriptive statistics, along with the list of survey organizations, are reported in Table A.1 and Table A.2 in the supplementary file, respectively.

\subsection{Results}

Results for gender differences in the aggregated feminine and masculine issue areas are presented in Table $3.1 .^{3}$ The positive and statistically significant coefficient $(p<$ 0.001) on the gender variable in models 1 and 2 show that female respondents are far more likely to state feminine issues as the most important problems facing their country. Compared with respondents who identify as independent, republicans are less likely and democrats are more likely to view feminine issues as the most important problems. Models also show that respondents from Southern states are more likely to choose feminine issue areas as the most important problem, which, at first glance, comes as a surprise. However, a closer look at the differences in individual policy categories reveals that the regional differences in feminine issues are driven by such issues as family, national values and culture, crime and corruption. Age and income level are negatively associated, education is positively associated with the likelihood of stating feminine issues as the most important problem.

Models 3 and 4 indicate that female respondents, compared with their male coun-

\footnotetext{
${ }^{2}$ Alternative dependent variables were utilized for robustness. Issues related to crime, immigration problems, inflation and industrial policy were coded as masculine issues, whereas issues related to old age pension and war casualties were coded as feminine issues. Results have not changed.

${ }^{3}$ Table reports coefficients (not odds ratios) obtained from logistic regressions.
} 
terparts, are significantly less likely to identify masculine policies as the most important problems facing their country. Surprisingly, while respondents who identify as republican are more concerned with masculine issues both democrats and republicans are more likely than independents to state masculine policies as the most important problems. One possibility might be that partisans pay utmost attention to the issues that receive national media coverage such as foreign policy, national defense, unemployment, and fiscal policy. Income level and age are negatively associated with the identification of masculine policies as the most important problems.

All in all, results from Table 2 indicate that female respondents differ significantly from their male counterparts in the types of issues they consider as the most important problems facing their country. Furthermore, these differences are substantively meaningful. In order to interpret the substantive impact of gender, I estimate simulation scenarios holding independent variables constant at their means or modes. ${ }^{4}$ According to this, switching from female to male increases (decreases) the likelihood of identifying feminine (masculine) issues as the most important problems by 30 percent (15 percent). These results imply that gender differences in feminine issues are stronger than the gender differences in masculine issues.

I delve further into gender differences in policy priorities by disaggregating feminine and masculine issues to examine the effect of gender on individual policy categories. ${ }^{5}$ I estimate logistic regression models that predict the likelihood of a respondent mentioning given policy issues as the most important problems, wherein the dependent variables are 29 policy categories coded by Heffington et al. (2017) using the Singer coding scheme. The figure 3.1 depicts the odds ratios on the variable female that are derived from 29 empirical models. An odds ratio of 1.50, for instance, means that females are about half as more likely to list the given issue as male respondents.

\footnotetext{
${ }^{4}$ Clarify (Tomz et al. 2003) was utilized to estimate the simulation scenarios.

${ }^{5}$ Since some policy issues have been mentioned relatively less frequently by the respondents, I replicate these models using penalized (i.e., rare event) logistic regressions. Results have remained the same.
} 
Table 3.1: Gender Differences in Attention to Feminine and Masculine Issues

\begin{tabular}{|c|c|c|c|c|}
\hline & $\frac{\text { Model 1 }}{\text { Feminine }}$ & $\frac{\text { Model } 2}{\text { Feminine }}$ & $\frac{\text { Model } 3}{\text { Masculine }}$ & $\frac{\text { Model 4 }}{\text { Masculine }}$ \\
\hline Female & $\begin{array}{l}0.347^{* * *} \\
(0.00691)\end{array}$ & $\begin{array}{l}0.324^{* * *} \\
(0.00614)\end{array}$ & $\begin{array}{c}-0.222^{* * *} \\
(0.00610)\end{array}$ & $\begin{array}{c}-0.217^{* * *} \\
(0.00514)\end{array}$ \\
\hline Republican & $\begin{array}{l}-0.0234^{*} \\
(0.00926)\end{array}$ & $\begin{array}{l}-0.0456^{* * *} \\
(0.00822)\end{array}$ & $\begin{array}{l}(0.00811) \\
0.00759\end{array}$ & $\begin{array}{l}0.101^{* * *} \\
(0.00693)\end{array}$ \\
\hline Democrat & $\begin{array}{l}0.0773^{* * *} \\
(0.00829)\end{array}$ & $\begin{array}{l}0.0670^{* * *} \\
(0.00738)\end{array}$ & $\begin{array}{l}0.00759 \\
(0.00740)\end{array}$ & $\begin{array}{l}0.0355^{* * *} \\
(0.00636)\end{array}$ \\
\hline Region: South & $\begin{array}{l}0.0251^{* * *} \\
(0.00726)\end{array}$ & $\begin{array}{l}0.0699 * * * \\
(0.00656)\end{array}$ & $\begin{array}{l}-0.0806^{* * *} \\
(0.00657)\end{array}$ & $\begin{array}{l}-0.122^{* * *} \\
(0.00577)\end{array}$ \\
\hline Age (log) & $\begin{array}{c}-0.192^{* * *} \\
(0.00905)\end{array}$ & & $\begin{array}{l}0.0495^{* * *} \\
(0.00816)\end{array}$ & \\
\hline Education & $\begin{array}{l}0.129^{* * *} \\
(0.00433)\end{array}$ & & $\begin{array}{l}0.00234 \\
(0.00379)\end{array}$ & \\
\hline Income Level & $\begin{array}{l}-0.0239^{* * *} \\
(0.00345)\end{array}$ & & $\begin{array}{l}0.0153^{* * *} \\
(0.00308)\end{array}$ & \\
\hline Democratic President & $\begin{array}{l}0.312^{* * *} \\
(0.0268)\end{array}$ & $\begin{array}{l}0.343^{* * *} \\
(0.0256)\end{array}$ & $\begin{array}{l}0.135^{* * *} \\
(0.0292)\end{array}$ & $\begin{array}{l}0.130^{* * *} \\
(0.0277)\end{array}$ \\
\hline Constant & $\begin{array}{l}-0.953^{* * *} \\
(0.0961)\end{array}$ & $\begin{array}{l}-3.770^{* * *} \\
(0.0624)\end{array}$ & $\begin{array}{l}0.0163 \\
(0.107)\end{array}$ & $\begin{array}{l}-1.285^{* * *} \\
(0.0609)\end{array}$ \\
\hline Year Fixed Effects & Yes & Yes & Yes & Yes \\
\hline Survey Organization Fixed Effects & Yes & Yes & Yes & Yes \\
\hline Observations & 619,380 & 845,120 & 619,380 & 847,684 \\
\hline Log Likelihood & -275501.9 & -349798.2 & -331874.6 & -460241.6 \\
\hline Pseudo $\mathrm{R}^{2}$ & 0.086 & 0.094 & 0.053 & 0.063 \\
\hline
\end{tabular}

Robust standard errors in parentheses

$* * * p<0.01, * * p<0.05, * p<0.1$

The figure shows that there are significant gender differences in various policy areas, particularly in areas that are traditionally known as feminine and masculine issues. For instance, it is shown that the odds of mentioning health policy, poverty or housing as the most important problems among female respondents is 50 percent more than the odds of these policies being mentioned by male respondents. It is also clear from the figure that female respondents are more concerned with such issues as education policy, family issues, welfare, old age pension, crime, values, morals and culture, and 
Figure 3.1: Gender Differences in Individual Policy Areas

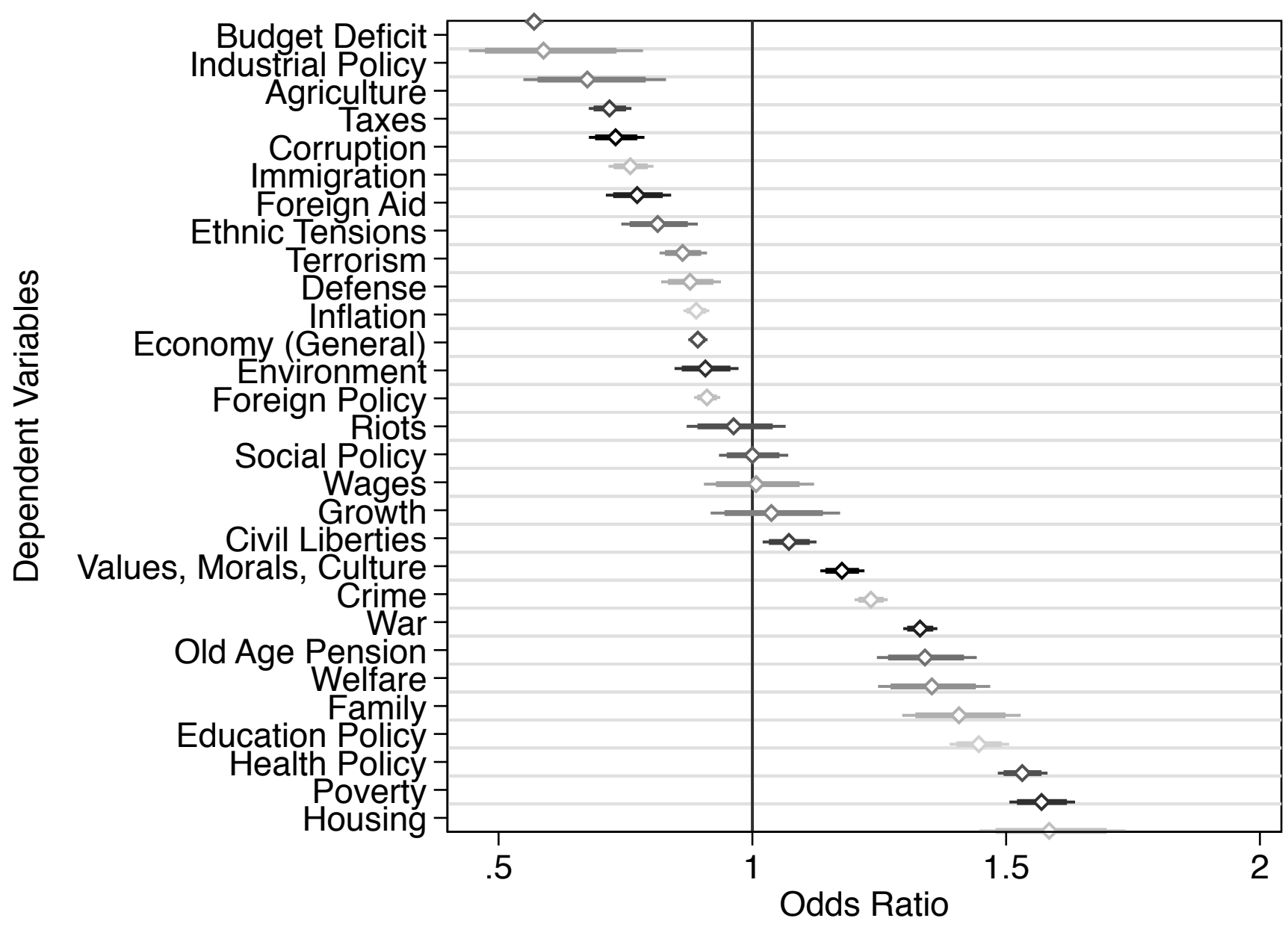

civil liberties. In contrast, male respondents are more likely to mention issues related to foreign policy (in general), foreign aid, inflation, economy (in general), industrial policy, agriculture, taxes, defense, terrorism, budget deficit, corruption, ethnic tensions, immigration, and environment as the most important problems facing their country.

Another research question that has received considerable scholarly attention is whether well-known gender differences in various aspects of political behaviors and attitudes have changed over time (Shapiro and Mahajan 1986; Beutel and Marini 1995; Norrander 1999; Atkeson and Rapoport 2003). According to this body of re- 
Figure 3.2: Gender Differences in Masculine and Feminine Issues by Decade
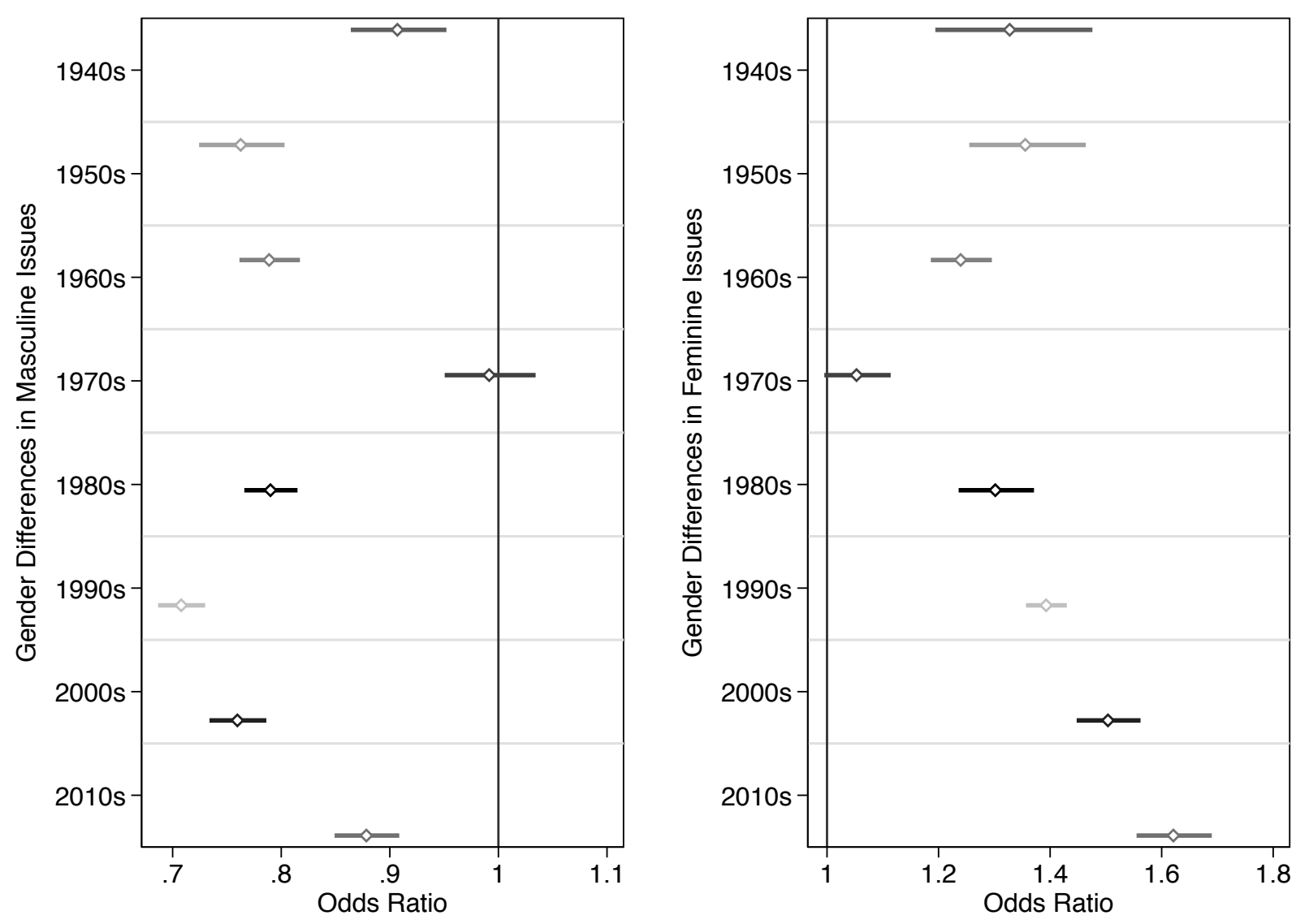

search, gender differences in issue attention may change over time due to changes in issue saliency, political sophistication and participation in political and economic life. I further interrogate the data to explore whether the gender differences shown in policy priorities are invariant across time. This is crucial, as finding inconsistent patterns over time would weaken the premise that gender differences are universal and caused by psychological dispositions. I replicate the models 2 and 4 presented in Table 2 on decade-only samples, as aggregate-level analyses of change in gender differences may fail to capture varying political and economic positions among men and women (see Norrander 1999). The odds ratios of the variable female from 16 logistic regression models are plotted in Figure 3.2. The figure suggests that gender 
differences in masculine and feminine issue areas have remained fairly stable, except the decade of 1970s. It is also clear from the figure that gender differences in feminine issues have grown over the past four decades, a finding that ties nicely with women's growing support for the Democratic party. Although a full explanation as to what explains the weakened gender differences in the 1970s is beyond the scope of this article, the breakdown of individual policy frequencies suggests that women became particularly concerned with the economy (i.e., inflation) and international affairs (i.e., foreign policy) in the 1970 s, both of which are traditionally known as masculine issues. Moreover, increases in attention to the economy and international affairs among women in the 1970s came at the expense of attention to such feminine issues as health, education, family issues, social welfare, which helps explain why gender differences in masculine and feminine issues shrunk in size in this particular period.

\subsection{The Saliency of 'Feminine-Masculine' Issues: A Difficult Case}

Figure 3.2 documenting gender differences in female-masculine issues on decade-only samples shows that women and men did not hold distinct policy priorities in the 1970s. Although restricting the analysis to decade-only samples increases the standard errors and reduces the chance of finding statistically significant results, the null or weak finding for gender differences in the 1970s may have been caused by increasing attention to the economy (i.e., inflation) and international affairs (i.e., foreign policy). In order to further explore the conditions under which gender differences tend to become smaller or disappear, I replicate the empirical models presented above based on various subsamples. One possibility is that extreme attention to urgent issues that are featured in national media may lead both men and women to concentrate their 
attention on highly salient issues, minimizing gender differences in policy priorities. To explore the viability of this explanation, I utilize a dataset that takes a systematic random sample of the New York Times Index since 1946, where "the sample is derived by coding the first entry on every odd-numbered page of the index". ${ }^{6}$ Both MIPD and the New York Times Index content-code policy categories using the Comparative Agendas Policy (CAP) coding scheme, allowing me to compare the public agenda to media agenda.

I first coded news entries as 'feminine' and 'masculine' issues and collapsed them biannually to create biannual frequencies of feminine-masculine issues. I then subtracted the mean of feminine issues featured biannually from the mean of masculine issues to find the periods with the most attention paid to masculine issues and the least to feminine issues. ${ }^{7}$ The main rationale behind finding the periods dominated with masculine issues is to explore whether gender differences disappear when information receivers, respondents, are exposed to a highly concentrated information stream. ${ }^{8}$ Creating a new sample based on 16 biannual periods with the highest level of media coverage of masculine issues and the lowest level of attention to feminine issues, ${ }^{9}$ I replicated my original models presented in the previous sections. If gender differences are driven by time and context, such differences in feminine and masculine issues should disappear or become much smaller due to the dominance of masculine issues in the news media.

\footnotetext{
${ }^{6}$ The New York Times Index. The Policy Agendas Project at the University of Texas at Austin, 2018. www.comparativeagendas.net. Accessed June 1, 2018.

${ }^{7}$ For instance, if the means of the news stories about masculine and feminine issues featured in the New York Times in a given period are 40 and 30 percent, respectively, then the mean difference for that year is 10 percent.

${ }^{8}$ Although some might find it misleading to use a single media source to analyze the media agenda, previous scholarship has shown that there are strong correlations in news coverage across outlets for highly salient issues (see Atkinson, Lovett and Baumgartner 2014).

${ }^{9}$ These years are $1946(2), 1947,1949,1950,1952,1954,1955,1956,1957,1960$ (2), 1964, 1974, 1980, 2004. The parantheses indicate the years with both six-month periods included in the sample. Since the public opinion in time $t$ should be affected by the news media coverage at time $t-1$, I lag the six-month periods in the analysis. As an example, all the surveys that were conducted in the first six-month of 2004 were matched with the news coverage data from the second six-month period of 2003.
} 
According to these results (not shown), gender differences in policy priorities in times of masculine-issue dominated periods are still highly significant. More specifically, in these periods, women were still more likely than men to consider feminine issues as the most important problems facing their society $(p<0.001)$. In other words, increasing issue attention to masculine issues and the disappearance of the feminine issues from the news media did not lead female respondents to shift their focus to masculine issues at the expense of the feminine ones. To summarize, gender differences in policy priorities are so striking that they did not disappear even when the news media focused attention on masculine issues such as the economy.

\subsection{Discussion}

This chapter sought to advance our understanding of the extent to which women differ from men in policy priorities by undertaking the most comprehensive study to test of the oft-cited gender differences in policy priorities. Analyzing as many as 686 public opinion surveys conducted in the US with over 930,000 respondents, I examine the extent to which women differ from men in 29 policy issues over the past 75 years. Drawing from previous scholarship in political behavior and various subfields of psychology, I argue that female-male differences in issue attention and policy priorities are much stronger than previously thought. Moreover, these differences are mostly invariant across time. Results based on a series of logistic regressions with year and survey fixed-effects reveal that female respondents are significantly more likely than men to consider issues related to war, housing, poverty, old age pension, welfare, family, education, health, civil liberties and crime as the most important problems facing their country. These policy areas are traditionally known as 'compassion' or 'feminine' issues (Huddy and Terkildsen 1993; Eagly et al. 2004; Page and Shapiro 2010; Funk and Philips 2018), as they are related to care and empowerment. In contrast, I found 
that male respondents are significantly more likely to list issues related to foreign policy, foreign aid, inflation, industrial policy, agriculture, taxes, defense, terrorism, budget deficit, corruption, ethnic tensions, immigration and environment as the most important problems facing their society. Except the case of environment, these policy areas are traditionally known as 'masculine' issues, as they are the symbols of order, survival, and hierarchy. In short, these findings are in line with the arguments proposed by evolutionary and social psychologists regarding female-male differences in psychological dispositions (Rushton et al. 1986; Geary 1988, 2005; DeSoto et al. 2007; Wood and Eagly 2012).

Although this chapter undertakes the most comprehensive test of the hypothesized gender differences in issue attention and policy priorities, the results presented here are far from a definitive test of this thesis. A growing number of political scientists turn to experimental methods utilized in neuropsychology to delve further into cognitive foundations of information processing. In a recent study, Jost et al. (2014) reviewed the neural basis of information processing anomalies (e.g., prejudice and stereotyping) and suggest "the beginning of a beautiful friendship" between political science and neuroscience, calling it 'political neuroscience' (but see Theodoridis and Nelson 2012). Schreiber and collaborators (2013) have undertaken a novel test of partisan differences in brain activities and documented substantial evidence that liberals and conservatives engage distinct cognitive processes when exposed to risk-taking behavior. Experimental studies examining sex differences in cognitive processes may prove useful in understanding the causal mechanism behind the linkages between gender and policy priorities. Based on the empirical evidence suggested by cognitive and neuropsychologists, one might expect to observe higher brain activity in women when subjects are exposed to material (e.g., news stories) related to care, harm and empowerment. Although a full answer to neuropsychological foundations of gender differences in policy priorities must await further study, the findings presented in this 
chapter are highly suggestive of gender differences in attitudinal dispositions that are invariant across time and space. 


\section{Chapter 4}

\section{Gender, Cognitive Styles and the Most Important Problems}

Following various lines of research in political science and psychology research, previous chapters have established that there are significant sex differences in the processing of societal cues, empathy and concern for problems facing society. I argued that these differences should have important implications for issue attention and agenda diversity, where I expect female respondents and representatives, compared with their male counterparts, to list a larger number of issues when given the opportunity to do so (via parliamentary speeches and survey questions). I also argued that the well-documented gender differences in issue attention to 'feminine' and 'masculine' issues can be explained by the same strands of research on gender differences in values, norms, and psychological dispositions. In this chapter I test my hypothesis that women list a larger number of issues when asked about the most important problems facing their country. For empirical analysis, I undertake two empirical tests of the hypothesized relationship: First, I capitalize on the European Election Study (EES) surveys conducted in 12 West European countries in 1999. These surveys are unique in that the respondents were asked seven open-ended most important prob- 
lem questions, which allows for much more variation as compared to standard MIP surveys. Secondly, I make use of a recently introduced and the most comprehensive dataset of most important problem surveys (Heffington, Park and Williams 2017).

This chapter seeks to advance our understanding of gender differences in public opinion by asking the following question: Do women attend to a larger number of societal issues when asked about the problems facing society due to well known sex-based differences in cognitive architectures? By analyzing the most important problem surveys in 12 European countries and the US, I test the argument that women differ from men in issue-carrying capacity, the scope of societal issues with which respondents are involved. The results based on multilevel mixed-effects Poisson regressions show that women choose to provide a larger number of answers when asked about the most important problems facing their country, a finding that is insensitive to various robustness checks and model specifications. In what follows I briefly revisit my theoretical expectations in regards to the agenda diversity of men and women. Next, I introduce the data and methods utilized in the study and then provide my empirical findings. The discussion section considers potential implications and shortcomings of these results.

\subsection{A Brief Overview of Theoretical Expectations}

The extant research in cognitive psychology and neuroscience finds that females and males have distinct information processing styles (Seidlitz and Diener 1998). Following this line of research, one of the questions that needs to be addressed concerns the extent to which women differ from men in receiving, encoding and rehearsing information about societal issues. According to this, Baron-Cohen argues, women are more likely to show concern for fairness, respond emphatically to the distress of others and value reciprocal relationships. A large body of research following Baron- 
Cohen's work found strong evidence for this argument and confirmed previous findings (Happe 1995; Baron-Cohen 2002; Schulte-Rüther et al. 2008). As the discussion in the previous chapters summarized, there is ample evidence that women show more concern for societal issues (i.g., higher empathy and ToM), respond more strongly to emotional stimuli and recall the encoded information in a more effective way should result in differing levels of issue-carrying capacity between men and women. Based on this empirical finding, I argue that women's advantage in empathic response and emotional information processing should lead them to prioritize the issues that fail to enter males' agenda.

\subsection{Study I: Evidence from 12 European Countries}

\subsubsection{Data and Methods}

The first part of the empirical investigation undertaken in the present study utilizes the European Election Study (EES) surveys conducted in 12 West European countries in $1999(\mathrm{~N}=13,549)$. The surveys were conducted during the summer of 1999, where computer-assisted phone interviews were utilized. The primary reason for utilizing this survey is straightforward: The 1999 EES surveys are unique in the sense that respondents were asked seven open-ended most important problem (MIP) questions, which provides us with enough variation to measure individuals' agenda diversity in an efficient way. The sample size of individual countries varies from 301 (Luxembourg) to 3,708 (Italy), where Italy, France, Spain, Denmark, Germany, the Netherlands and the UK have a sample size of 1,000 or larger.

Since the dependent variable is the number of MIP questions mentioned by each respondent and the data is not over-dispersed, I utilize Poisson regression. Although there is considerable variation between and within countries in the number of answers 
Table 4.1: Summary Statistics of the Variables

\begin{tabular}{lccccc}
\hline \hline \multicolumn{1}{c}{ Variable } & Mean & Std. Dev. & Min. & Max. & Obs \\
\hline Number of MIPs mentioned & 1.585 & 1.015 & 0 & 7 & 13549 \\
Female & 0.521 & 0.5 & 0 & 1 & 13549 \\
Education (logged) & 2.995 & 0.372 & 1.792 & 4.575 & 12704 \\
Age (logged) & 3.74 & 0.37 & 2.94 & 4.55 & 13522 \\
Attention to news about the economy & 2.574 & 0.894 & 1 & 4 & 13336 \\
Do you agree: "politics is too complicated" & 2.842 & 0.919 & 1 & 4 & 12998 \\
Attention to News about the Economy & 2.57 & 0.89 & 1 & 4 & 13336 \\
Satisfaction with Democracy & 0.55 & 0.49 & 0 & 1 & 13549 \\
MIP: the Economy & 0.32 & 0.46 & 0 & 1 & 13549 \\
Interest in politics & 2.465 & 0.877 & 1 & 4 & 13035 \\
Ideology (left-right scale) & 5.276 & 2.347 & 1 & 10 & 11430 \\
Frequency of watching TV news (days) & 5.489 & 2.102 & 0 & 7 & 13145 \\
Frequency of reading a newspaper (days) & 3.783 & 2.849 & 0 & 7 & 13068 \\
\hline
\end{tabular}

given to MIP questions, the majority of the respondents answered one or two MIP questions. Previous scholarship has shown that various factors may play some role in shaping how individuals' issue attention and agenda capacity. For instance, political sophistication, news readership, education and interest in politics are found to increase agenda capacity (Zaller 1990; Popkin 1991, McCombs and Zhu 1995; Wanta et al. 1995). Research on the effect of age on agenda capacity has produced inconsistent findings (Wanta et al. 1995; Peter and Claes 2003). Following previous scholarship, I utilize three sets of independent variables. Demographic variables include female, rural, age, education and social class. I expect the place of residence (rural vs. urban) to be an important factor that influences how people think about societal issues. Female and rural are dichotomous variables, with 1 indicating female and rural background, respectively. Age and social class are continuous variables that range from 18 to 94 and from 1 (working class) to 5 (upper class), respectively. The education 
variable measures age when stopped full-time education and ranges from 6 to 97 and it is log-transformed in the empirical models. ${ }^{1}$ To account for the cognitive capacity of individuals, such variables as interest in politics, news attention (reading and watching news), and the extent to which respondents have difficulty understanding politics are included in the analysis (see Zaller 1990; McCombs and Zhu 1995; Wanta et al. 1995; Peter and De Vreese 2003). The political interest and sophistication variables range from 1 to 4 , the latter measuring the respondent's agreement with the argument that 'politics is too complicated' ( $1=$ strongly disagree, $4=$ strongly agree). Newspaper and TV variables range from 0 (never) to 7 (seven days), indicating the respondent's frequency of reading a newspaper and of watching TV news. Finally, I control for respondent's ideological left-right self placement (1=left, $10=$ right) and for individual countries. Descriptive statistics are reported in Table 4.1.

\subsubsection{Results}

To the extent that my theory is correct, I would expect to female respondents to list a larger number of issues when asked about the most important problems facing their society. The main results from multi-level Poisson regression estimations are reported in Table 4.2. The first column presents the baseline model that explores the effect of sex on issue-carrying capacity when controlling for main sophistication and political variables. The models show that female respondents were significantly more likely to list a higher number of issues $(p<0.001)$. Among the independent variables, education, frequency of reading newspaper and interest in politics are positively associated with issue-carrying capacity $(p<0.01)$, which lends strong support for findings from previous scholarship (Wanta et al. 1995). That is, those who are better educated, read newspaper more frequently and have more interest in politics

\footnotetext{
${ }^{1}$ Those who had not stopped full-time education at the time of interviews were assigned their age.
} 
list a higher number of issues when asked about the most important problems facing their country.

These results are insensitive to the inclusion of other variables such as age, satisfaction with democracy, attention to the economy and the duration of interview. In fact, the coefficient of female becomes larger with the addition of various sociodemographic and political variables in the models and emerges as one of the most important predictors of issue-carrying capacity at the individual level. The coefficients of ideological self-placement, age, frequency of watching news carry negative signs, though they do not reach statistical significance. Political complication (i.e., 'politics too complicated') and ideology variables are negatively associated with issue-carrying capacity and come up statistically significant at $p<0.1$ only in one model. Respondents who are satisfied with democracy are significantly less likely to list a higher number of issues when asked about the most important problem. Finally, those who list the economy as the first most important problem and who pay attention to news about the economy are more likely to have a diverse political agenda.

To delve further into the link between sex and issue-carrying capacity, I simulate the substantive effects of the key predictors of interest while holding other variables at their mean or modes. Results suggest substantively and statistically meaningful $(p<0.01)$ changes in issue-carrying capacity when switching from male to female. Specifically, the probability of answering two or more MIP questions increases by 12 percent (from 0.54 to 0.61 ), three or more MIP questions by 17 percent (from 0.210 to 0.246 ), and four or more MIP questions by 28 percent (from 0.054 to 0.07 ) when switching from male to female. Additionally, the probability of answering no MIP question decreases by 27 percent (from 0.047 to 0.034 ) when switching from male to female.

To gain a better sense of these substantive impacts and rule out other causal paths, I replicated these simulations using various subsamples that allow me to compare the 
Table 4.2: Multilevel Mixed-Effects Poisson Regression on the Number of Most Important Problems

\begin{tabular}{|c|c|c|c|c|}
\hline & Model 1 & Model 2 & Model 3 & Model 4 \\
\hline Female & $\begin{array}{c}0.0685^{* * *} \\
(0.0159)\end{array}$ & $\begin{array}{c}0.0731^{* * *} \\
(0.0172)\end{array}$ & $\begin{array}{c}0.0600^{* * *} \\
(0.0166)\end{array}$ & $\begin{array}{c}0.0841^{* * *} \\
(0.0174)\end{array}$ \\
\hline Politics too Complicated & $\begin{array}{c}-0.00599 \\
(0.00896)\end{array}$ & $\begin{array}{c}-0.0165^{*} \\
(0.00963)\end{array}$ & & $\begin{array}{c}-0.0128 \\
(0.00967)\end{array}$ \\
\hline Interest in Politics & $\begin{array}{c}0.0875^{* * *} \\
(0.0102)\end{array}$ & $\begin{array}{c}0.0789^{* * *} \\
(0.0112)\end{array}$ & & $\begin{array}{c}0.0600^{* * *} \\
(0.0120)\end{array}$ \\
\hline Ideology: Left-Right (1-10) & $\begin{array}{c}-0.00189 \\
(0.00335)\end{array}$ & $\begin{array}{l}-0.00251 \\
(0.00368)\end{array}$ & $\begin{array}{c}-0.00608^{*} \\
(0.00359)\end{array}$ & $\begin{array}{l}-0.00355 \\
(0.00371)\end{array}$ \\
\hline Frequency of Watching TV News & $\begin{array}{l}-0.00536 \\
(0.00403)\end{array}$ & $\begin{array}{c}-0.00466 \\
(0.00434)\end{array}$ & & $\begin{array}{c}-0.00689 \\
(0.00444)\end{array}$ \\
\hline Frequency of Reading Newspaper & $\begin{array}{c}0.0134^{* * *} \\
(0.00308)\end{array}$ & $\begin{array}{c}0.00957^{* * *} \\
(0.00336)\end{array}$ & & $\begin{array}{r}0.00905^{* * *} \\
(0.00341)\end{array}$ \\
\hline Education (logged) & $\begin{array}{c}0.107^{* * *} \\
(0.0280)\end{array}$ & $\begin{array}{c}0.130^{* * *} \\
(0.0330)\end{array}$ & & $\begin{array}{c}0.135^{* * *} \\
(0.0338)\end{array}$ \\
\hline Duration of Interview (logged) & & $\begin{array}{c}0.223^{* * *} \\
(0.0397)\end{array}$ & $\begin{array}{c}0.246^{* * *} \\
(0.0385)\end{array}$ & $\begin{array}{c}0.224^{* * *} \\
(0.0402)\end{array}$ \\
\hline Age (logged) & & & $\begin{array}{l}-0.0201 \\
(0.0224)\end{array}$ & $\begin{array}{r}-0.00332 \\
(0.0248)\end{array}$ \\
\hline Attention to News: the Economy & & & $\begin{array}{c}0.0864^{* * *} \\
(0.00964)\end{array}$ & $\begin{array}{c}0.0552^{* * *} \\
(0.0108)\end{array}$ \\
\hline Satisfaction with Democracy & & & $\begin{array}{c}-0.0451^{* *} \\
(0.0180)\end{array}$ & $\begin{array}{c}-0.0545^{* * *} \\
(0.0186)\end{array}$ \\
\hline MIP: the Economy & & & $\begin{array}{c}0.0691^{* * *} \\
(0.0180)\end{array}$ & $\begin{array}{c}0.0625^{* * *} \\
(0.0185)\end{array}$ \\
\hline Constant & $\begin{array}{c}-0.250^{* *} \\
(0.0996)\end{array}$ & $\begin{array}{c}-0.937^{* * *} \\
(0.171)\end{array}$ & $\begin{array}{c}-0.549^{* * *} \\
(0.148)\end{array}$ & $\begin{array}{c}-1.005^{* * *} \\
(0.190)\end{array}$ \\
\hline Subject-Specific Random Effects & $\begin{array}{l}0.129^{* *} \\
(0.0559)\end{array}$ & $\begin{array}{c}0.0875 * * \\
(0.0384)\end{array}$ & $\begin{array}{c}0.0553^{* *} \\
(0.0246)\end{array}$ & $\begin{array}{c}0.0732 * * \\
(0.0324)\end{array}$ \\
\hline Log Likelihood & -14284 & -11963.6 & -12705 & -11914.2 \\
\hline Observations & 10,040 & 8,071 & 8,572 & 8,052 \\
\hline Number of Countries & 15 & 14 & 14 & 14 \\
\hline
\end{tabular}

issue-carrying capacity of female respondents with low political sophistication and political interest to that of male respondents with high political sophistication and political interest. As news consumption, political interest and political sophistication have been identified as important predictors of issue-carrying capacity (McCombs and 
Zhu 1995; Peter and De Vreese 2003), hypothetical manipulation of these variables in a way that reduces sex differences in issue-carrying capacity might tell us more about the substantive impact of sex on information processing. Results based on the subsample that consists of female respondents with low news consumption ( 5 or fewer days a week) and male respondents with high news consumption (5 or more days a week) reveal that the probability of answering four or more MIP questions increases by 24 percent, and three or more MIP questions by 16 percent when switching from male to female. Results based on the subsample that consists of female respondents with low political sophistication ('strongly agree' or 'agree' with the statement that "politics is too complicated") and low interest in politics ('not at all interested' or 'a little interested'), and male respondents with high political sophistication and interest ('strongly disagree' or 'disagree' with the statement that "politics is too complicated") show that the probability of answering four or more MIP questions increases by 20 percent, three or more MIP questions by 15 percent when switching from male to female. All in all, these findings imply that sex differences in agenda diversity do not disappear even when news consumption, political sophistication and political interest variables favor male respondents. ${ }^{2}$

\subsection{Study II: Evidence from the US}

\subsubsection{Data and Methods}

The second part of the empirical investigation of sex differences in agenda diversity utilizes the 'Most Important Problem' Dataset (MIPD) (Heffington, Park and Williams 2017). The MIPD contains the individual-level responses to open-ended

\footnotetext{
${ }^{2}$ These results are insensitive to alternative specifications of core models. More specifically, the inclusion of four new variables, religion, size of household, social class, and work situation has left the sex differences in agenda diversity unchanged.
} 
'most important problem' questions from 1935-2015 in the US. On the one hand, the MIPD constitutes a significant improvement over the EES dataset as it allows me to examine individuals' issue-carrying capacity over time and across various demographic groups. On the other, it contains limited to no information about individuals' news consumption, political interest and sophistication, and therefore requires us to proceed with caution in interpreting results documented based on our sample. Still, the MIPD allows me to control for numerous sociodemographic and political factors that may play a role in shaping individuals' agenda capacity.

Although the dataset originally contains information from over 930,000 individuals, the great majority of these surveys have either one or two MIP questions, which does not provide us with reasonable variation in our dependent variable. For this reason, I focus only on the surveys with three MIP questions and this leaves us with 94 nationally representative surveys that were conducted between 1960 and 2015 with over 110,000 respondents. While the large majority of surveys were conducted in the post-Clinton period, the surveys from previous administrative terms are large enough to allow for statistical comparisons.

I estimate a series of Poisson regressions with robust standard errors clustered by survey, ${ }^{3}$ as the dependent variable measures the number of MIP questions answered by each respondent. I utilize three sets of independent variables: Socio-demographic variables include education, age (logged), income level (quartile), region of residence (i.e., south) and marital status. Political variables are presidential approval and partisan identification (i.e., Independent and Republican). Similar to the democratic satisfaction variable utilized in the first section of the empirical investigation, presidential approval is included to account for the effect of political satisfaction on issue-carrying capacity. The final set of variables includes decade (i.e., 1970s, 1990s, and 2000s) and survey dummies (i.e., interview method, Gallup surveys). Since attention to the

\footnotetext{
${ }^{3}$ These models were replicated using Multilevel Mixed-Effects Poisson Regression; the results remained the same.
} 
economy may shape the issue-carrying capacity in a significant way, I also include a variable that accounts for those who viewed the economy as the most important problem. Descriptive statistics are reported in Table 4.3.

Table 4.3: Measurement of Dependent and Independent Variables

\begin{tabular}{lccccc}
\hline \hline \multicolumn{1}{c}{ Variable } & Mean & Std. Dev. & Min. & Max. & N \\
\hline Number of MIP Answers & 1.401 & 0.854 & 0 & 3 & 110796 \\
Female & 0.502 & 0.5 & 0 & 1 & 110796 \\
Presidential Approval & 0.468 & 0.499 & 0 & 1 & 93406 \\
Republican & 0.284 & 0.451 & 0 & 1 & 110796 \\
Democrat & 0.454 & 0.498 & 0 & 1 & 110796 \\
Southern State & 0.349 & 0.477 & 0 & 1 & 107986 \\
Age (logged) & 3.89 & 0.388 & 2.89 & 4.595 & 106503 \\
Education Level & 3.444 & 0.922 & 1 & 5 & 109779 \\
Household Income (quartiles) & 2.513 & 1.089 & 1 & 4 & 100305 \\
Marital Status & 0.568 & 0.495 & 0 & 1 & 92263 \\
MIP: the Economy & 0.362 & 0.48 & 0 & 1 & 110796 \\
Interview Method: Cellular & 0.623 & 0.485 & 0 & 1 & 110796 \\
Gallup Survey & 0.683 & 0.465 & 0 & 1 & 110796 \\
Decade: 1970s & 0.028 & 0.166 & 0 & 1 & 110796 \\
Decade: 1990s & 0.184 & 0.387 & 0 & 1 & 110796 \\
Decade: 2000s & 0.166 & 0.372 & 0 & 1 & 110796 \\
\hline
\end{tabular}

\subsubsection{Results}

Results based on a series of Poisson regressions are reported in Table 4.4. The baseline model includes the main explanatory variable, gender, along with three decade dummies. All four models show that women are significantly more likely to list a larger number of issues when asked about the most important problems facing their country $(p<0.001)$, even after controlling for various socio-demographic, political and survey-specific variables. It is noteworthy that the predictive power of gender 
is at least as large as one's education level and presidential approval, partisan affiliation, and income level (among other variables). Education is positively associated with issue-carrying capacity and it comes up statistically significant $(p<0.001)$. Being republican and residing in the south are negatively associated with issue-carrying capacity and statistically significant at $p<0.05$. I replicated Model 8 based on the subsamples of southern, republican, democrat, high-education, low-education respondents, and those who approve and disapprove the president (not shown). In no model gender loses its statistical significance of $p<0.001$. In other words, sex differences in issue-carrying capacity are significant within and across socio-demographic and political groups.

Simulating the substantive impact, I show that changing gender hypothetically from male to female while holding all other variables constant at their means or modes produces substantively meaningful increases in the probability of answering 2 or 3 MIP questions. Specifically, switching from male to female increases the likelihood of answering three MIP questions by 20 percent (from 0.119 to 0.143 ), and answering 2 or more questions by 13 percent (from 0.281 to 0.316 ). Furthermore, this change decreases the probability of answering one or no MIP question by 5 percent (from 0.719 to 0.684 ). Taken together, these results lend strong support for my hypothesis that women attend to a larger number of societal issues.

A final concern needs to be addressed before I discuss the implications of these findings. One may argue that sex differences in response rates in public opinion surveys may be the driving force behind observed sex differences in issue-carrying capacity. In particular, women may have a stronger tendency than men to answer survey questions due to different socializations. To rule out this potential explanation for higher number of MIP answers in women's responses, I estimate a series of penalized logistic regressions predicting the effect of gender on 'no response' in various survey items. I find no statistical effect of gender on 'no response' for questions 
Table 4.4: Poisson Regression on the Number of Most Important Problems

\begin{tabular}{|c|c|c|c|c|}
\hline & Model 1 & Model 2 & Model 3 & Model 4 \\
\hline Female & $0.0250^{* * *}$ & $0.0200^{* * *}$ & $0.0348^{* * *}$ & $0.0427^{* * *}$ \\
\hline Presidential Approval & & & $(0.00703)$ & $\begin{array}{c}(0.00460) \\
-0.0458^{* * *} \\
(0.0142)\end{array}$ \\
\hline Republican & & & & $\begin{array}{c}-0.0208^{* *} \\
(0.00864)\end{array}$ \\
\hline Democrat & & & & $\begin{array}{c}0.0117 \\
(0.0118)\end{array}$ \\
\hline Southern State & & & & $\begin{array}{c}-0.00959^{* *} \\
(0.00480)\end{array}$ \\
\hline Age (logged) & & & $\begin{array}{c}0.0436^{* * *} \\
(0.0119)\end{array}$ & $\begin{array}{c}0.0624^{* * *} \\
(0.0115)\end{array}$ \\
\hline Education & & & $\begin{array}{c}0.0103 \\
(0.00784)\end{array}$ & $\begin{array}{c}0.0213^{* * *} \\
(0.00419)\end{array}$ \\
\hline Household Income (quartiles) & & & $\begin{array}{c}0.0110^{* *} \\
(0.00464)\end{array}$ & $\begin{array}{c}0.00627^{*} \\
(0.00370)\end{array}$ \\
\hline Marital Status & & & $\begin{array}{c}0.0246^{* * *} \\
(0.00711)\end{array}$ & $\begin{array}{c}0.00989^{* *} \\
(0.00497)\end{array}$ \\
\hline MIP: the Economy & & & $\begin{array}{c}0.163^{* * *} \\
(0.0372)\end{array}$ & $\begin{array}{c}0.162^{* * *} \\
(0.0375)\end{array}$ \\
\hline Interview Method: Cellular & & $\begin{array}{c}-0.429^{* * *} \\
(0.138)\end{array}$ & $\begin{array}{c}-0.392^{* *} \\
(0.160)\end{array}$ & $\begin{array}{l}-0.0361 \\
(0.0474)\end{array}$ \\
\hline Gallup Survey & & $\begin{array}{c}0.138 \\
(0.0956)\end{array}$ & $\begin{array}{l}0.0844 \\
(0.147)\end{array}$ & $\begin{array}{l}0.0987 \\
(0.138)\end{array}$ \\
\hline Decade: 1970s & $\begin{array}{c}0.451^{* * *} \\
(0.0737)\end{array}$ & $\begin{array}{c}0.173 \\
(0.145)\end{array}$ & $\begin{array}{c}0.199 \\
(0.176)\end{array}$ & $\begin{array}{c}0.511^{* * *} \\
(0.106)\end{array}$ \\
\hline Decade: 1990 s & $\begin{array}{c}0.118 \\
(0.119)\end{array}$ & $\begin{array}{l}-0.207 \\
(0.171)\end{array}$ & $\begin{array}{l}-0.251 \\
(0.254)\end{array}$ & $\begin{array}{l}0.0629 \\
(0.276)\end{array}$ \\
\hline Decade: 2000 s & $\begin{array}{l}-0.0170 \\
(0.0439)\end{array}$ & $\begin{array}{c}-0.285^{* *} \\
(0.122)\end{array}$ & $\begin{array}{l}-0.232^{*} \\
(0.122)\end{array}$ & $\begin{array}{c}0.0116 \\
(0.0305)\end{array}$ \\
\hline Constant & $\begin{array}{c}0.289^{* * *} \\
(0.0401)\end{array}$ & $\begin{array}{c}0.569^{* * *} \\
(0.131)\end{array}$ & $\begin{array}{c}0.266 \\
(0.196)\end{array}$ & $\begin{array}{l}-0.187 \\
(0.122)\end{array}$ \\
\hline Log Likelihood & -146776 & -145790 & -107457 & -88917 \\
\hline Clustered Surveys & 94 & 94 & 79 & 73 \\
\hline Observations & 110,796 & 110,796 & 82,173 & 69,804 \\
\hline
\end{tabular}

Robust standard errors in parentheses

$* * * p<0.01, * * p<0.05, * p<0.1$

concerning age, education, ideology, and marital status. In fact, women are significantly less likely to answer various questions such as those concerning income, social 
class, partisan affiliation and presidential approval $(p<0.01)$. Results based on the data from the EES surveys follow a similar pattern, indicating that there is no sex differences in response rates for the frequency of watching TV news and interest in politics, while women are significantly less likely to answer questions concerning ideology and the frequency of reading newspaper. This implies that the sex differences in issue-carrying capacity documented in the present study are not a byproduct of sex differences in survey response favoring women.

\subsection{Discussion}

Although cognitive processes have long been thought to play a key role in human decision making (Tourangeau and Rasinski 1988; Zaller and Feldman 1992; Jones 2001; Taber 2003; Simon 2013), cognitive and neuropsychological foundations of information processing have received scant academic attention in political science research. This is of great importance particularly because studies in various subfields of psychology have documented substantial evidence that political and social attitudes can best be understood as structures embedded in long-term memory (Fazio and Williams 1986; Fazio et al. 1986) and that both social, cognitive and neural structures shape our perceptions and judgements of social and political stimuli (see Lieberman 2000; Ochsner and Lieberman 2001; Lieberman et al. 2003; Adolphs 2003, 2009). Therefore, it is important to acknowledge the role that social and biological forces may have played in shaping gender differences in information processing. As political scientists Hatemi and McDermott $(2012,117)$ forcefully argue, although genes do not determine any political and social behavior, "they provide the platform for the synthesis of proteins which then trigger a series of chemical processes which have neurological, cognitive, and emotive implications among other effects, dependent on environmental

cues" (also see Oxley et al. 2008; Verhulst et al. 2012; Hatemi et al. 2010; Jost et al. 
2014).

Drawing together research on human cognition and political behavior, this study introduces a powerful approach that advances our knowledge of systematic sex differences in information processing. Specifically, I argue that women's advantage in empathic response, concern for societal issues and emotional memory results in higher levels of issue-carrying capacity for women. Utilizing data from twelve European countries and the US, I find strong support for this argument. These findings are robust to different model specifications and robustness checks. The differences in issue-carrying capacity between men and women held even when I established simulation scenarios in which gender differences in issue-carrying capacity should be minimized. According to this, women with low political sophistication, political interest and news consumption, on average, attend to a wider range of issues than men with high political sophistication, political interest and news consumption. These findings imply that the gender of respondents plays a significantly larger role in shaping the individuals' issue-carrying capacity. I delve further into the implications of these findings in Chapter 6 .

It is of great importance to note the limitations of these findings. Although answers to the most important problem (MIP) surveys are arguably one of the most efficient and effective ways of measuring issue-carrying capacity in a cross-national setting, this study is far from a definitive test of the socio psychological foundations of gender differences in public opinion. A full answer to the question as to whether women differ from men in political information processing must await further study, ideally conducted in an experimental setting. The fact that the number of answers to MIP questions is heavily skewed to the right, with most respondents providing a limited number of answers, leads to difficulties interpreting the substantive impact of the main variables of interest. Additionally, the survey questions at our disposal do not allow us to examine the speed with which respondents identify the most important 
problems facing their country. Research on human cognition has shown that there are significant sex differences in the speed with which subjects respond to 'intuitive' (requiring no time) and 'deliberative' (requiring time) signals and questions (Brosnan et al. 2014). Future research needs to pay careful attention to both quantitative and qualitative differences in information processing patterns at the individual level. 


\section{Chapter 5}

\section{Representatives' Information Processing}

Chapter 3 and 4 show that women differ from men in issue attention and issuecarrying capacity. More specifically, I showed that women selectively focus more on what scholars call 'feminine' (or 'compassion') issues, whereas men pay particular attention to 'masculine' issues, and that women list a larger number of issues when asked about the most important problems facing their society. While political elites are expected to be more informed about governance, recent studies show that political elites are susceptible to error in judgement and disproportionate information processing (Arceneaux, Dunaway and Soroka 2018; Sheffer et al. 2018). In a recent study, Arceneaux and collaborators examined the threat sensitivity of legislators in the US and found that, like ordinary citizens, political elites' decisions are heavily influenced by psychophysiological threat sensitivity. Since my theoretical expectations draw on some universal assumptions of human choice and information processing, the finding that women attend to a wider range of societal issues should hold among political elites as well.

An empirical test of my theory based on a sample of political elites is crucial in 
exploring gender differences in information processing for at least two other reasons. First, the survey data do not allow me to control for various factors that are potentially correlated with both the dependent and independent variables. By analyzing political elites, I minimize the "unobserved heterogeneity" because political elites, compared with voters, are naturally much more homogenous in political sophistication, interest in politics and motivations (see Nuemayer and Plümper 2017). Secondly, the analysis of legislative speeches allows for much more variation in the scope of societal issues individuals can choose to focus on, as most representatives serve in legislatures for years and frequently find the chance to express interest in societal issues. For this reason, I test my hypothesis using an original dataset of parliamentarians who served in the Grand National Assembly of Turkey between 2002 and 2011, along with over 18,000 parliamentary speeches made by these representatives.

As I discussed previosly, I use the concept entropic agenda, not issue-carrying capacity, for the analysis of parliamentary speeches. Entropic agenda is a more suitable concept to measure the scope of issues legislators choose to focus on, as issue-carrying capacity might mistakenly lead readers to think of legislators with more speeches as 'high issue-carrying capacity' individuals. However, a legislator should be considered as having 'low issue-carrying capacity' if she speaks only about a single issue, even if she makes dozens of speeches about the given issue. This is because, unlike survey respondents, legislators have the chance to express interest in individual policy issues multiple times.

\subsection{The Turkish Case}

Turkey has been an electoral democracy since the introduction of multiparty elections in 1950, though the democratic process has been interrupted several times by brief military interventions. A large number of women have served as representatives in 
the Grand National Assembly of Turkey (GNAT) since the introduction of universal suffrage in 1935. Since then, Turkey has lagged behind Western democracies in terms of the representation of women in parliament. During the period I cover in this study (2002-2011), women representation in the parliament was 7 percent. Although this rate increased to 15 percent in the consecutive legislative terms between 2011 and 2017, data from these terms were not made completely available by the GNAT archives.

Turkey arguably constitutes a least likely case of finding female-male differences in entropic agenda for at least two reasons. First, as detailed interviews with representatives in Turkey shows, female representatives are reluctant to differentiate themselves from their male counterparts in policy priorities and parliamentary activities, as the Turkish parliamentary culture discourages gender-based differentiation in policy agendas (Ayata and Tutuncu 2008). As one of the interviewees stated in Ayata and Tutuncu's $(2008,465)$ study, "in order for women MPs to be successful in Turkish parliamentary culture, they have to be quarrelsome like men MPs." Indeed, a recent study exploring the underrepresentation of girls and women in science, technology, engineering, and mathematics (STEM) fields paradoxically found that countries with high levels of gender equality such as Finland have largest educational gender inequalities, indicating that societal pressures lead girls and women to resemble their male counterparts in their educational and occupational choices (Stoet and Geary 2018). That is, in countries with higher gender inequalities, women in leadership positions should be discouraged to differentiate themselves from their male counterparts. Secondly, institutional incentives may discourage gender differences in entropic agenda. Recent studies show that party selectorates in Turkey reward MPs who signal issue expertise and focus on a narrower range of issues with a better rank in the party list (Yildirim, Kocapinar and Ecevit 2017). Therefore, entropic agenda at the individual level should be discouraged for all MPs in general and for female MPs in particular, 
given the highly competitive nature of the Turkish parliament for women.

Parliamentary speeches provide a unique opportunity to observe policy priorities for several reasons (Laver, Benoit and Garry 2003; Slapin and Proksch 2010; Proksch and Slapin 2010; Baumann, Debus and Klingelhöfer 2017). First, parliamentary statements are low-cost and discipline-free initiatives. MPs have the liberty to take the floor without obtaining the permission of the party leadership and address any issue of their choosing. Secondly, as Bäck and Debus (2016, 16) put it, parliamentary speeches, compared with other legislative activities, are less prone to selection bias because "although controversial issues may give rise to more speeches, even the most uncontroversial ones will attract some attention from MPs." That is, parliamentary speeches have much more variation in terms of issues covered than other types of parliamentary activities and this allows for a fine-grained analysis of entropic agenda.

\subsection{Data and Methods}

I utilize original datasets of the biographies of 1,100 MPs and over 18,000 statements made by these MPs during the period of 2002-2011. I extracted the statements from the website of the Grand National Assembly of Turkey (GNAT). Two coders participated in the coding process after receiving intense training until the inter-coder reliability reached 90 percent. Within the framework of the Comparative Agendas Project (CAP), speeches were content-coded based on the CAP's codebook. I then collapsed the content-coded speeches by MPs to match with MPs' biographical information and political characteristics.

Shannon's H (entropy) is utilized as the dependent variable to measure issue diversity, which is the sum of probabilities of the different possible issue categories for each MP. This is a non-normalized diversity index that ranges from 0 to 2.50, with larger numbers indicating higher issue diversity (see Table 2.1). Scholars of politi- 
cal agenda setting increasingly use Shannon's entropy to measure agenda diversity (e.g., McCombs and Zhu 1995; Jones and Baumgartner 2005; Alexandrova, Carammia and Timmermans 2012), which is arguably superior to other diversity measures (Boydstun, Bevan and Thomas 2014).

Previous scholarship has shown that electoral motivations and role orientations affect MPs' engagement in parliamentary activities (Carey and Shugart 1995; Ciftci and Yildirim 2017); therefore, it is important to control for various political and sociodemographic factors. For this reason, based on the GNAT archives, I collected data about the political and demographical characteristics of representatives. These variables include electoral safety, opposition status and district magnitude, gender, age, localness (born in constituency), and education. Electoral safety is calculated by subtracting MP's position on the party list from the number of seats won by MP's party in that electoral province. In other words, this variable measures the MP's distance to the last available seat in his or her electoral province, where electoral safety becomes larger as the distance grows. Opposition status indicates whether the MP is a member of an opposition party and district magnitude measures the number of parliamentary seats allocated to each electoral province. Localness indicates whether the MP was born in his or her regional constituency. In addition, I control for the legislative term and total number of speeches made by each MP. Summary statistics are reported in Table 5.1.

\subsection{Results}

To the extent that my theory is correct, I would expect the female parliamentarians to attend to a wider range of policy issues in the parliament. Results based on OLS models testing this hypothesis are reported in Table 2. The baseline model includes the variables female, speech volume and electoral safety, and shows that female MPs 
Table 5.1: The Political and Demographic Characteristics of Representatives

\begin{tabular}{lccccc}
\hline \hline & $\mathrm{N}$ & Mean & Std. Dev. & Min. & Max. \\
\hline Opposition & 1,040 & 0.362 & 0.48 & 0 & 1 \\
Female & 1,040 & 0.0692 & 0.254 & 0 & 1 \\
$22^{\text {nd }}$ Term & 1,040 & 0.502 & 0.5 & 0 & 1 \\
Age & 1,040 & 49.58 & 8.609 & 30 & 85 \\
Total Speech & 1,040 & 20.54 & 29.48 & 0 & 359 \\
Speech (log) & 1,036 & 2.346 & 1.185 & 0 & 5.883 \\
Electoral Safety & 1,003 & 2.209 & 2.632 & 0 & 15 \\
Localness & 1,040 & 0.646 & 0.478 & 0 & 1 \\
Shannon's Entropy & 1,040 & 1.705 & 0.612 & 0.47 & 3 \\
H-H Index (normalized) & 1,040 & 0.619 & 0.226 & 0 & 1 \\
Education & 1,040 & 2.908 & 0.322 & 1 & 3 \\
District Magnitude & 1,040 & 10.74 & 8.474 & 2 & 31 \\
\hline
\end{tabular}

speak about a wider range of issues, as indicated by the positive coefficient of the variable female. The R-squared obtained from the baseline model indicates that these three variables do a good job of explaining the variation in the dependent variable. These results hold even after controlling for sociodemographic and political characteristics of the representatives. The variable female carries a positive sign and statistically significant at $p<0.05$ and $p<0.01$ levels in all five models. Model 5 indicates that switching from male to female increases entropy score by more than 11 percent. Additionally, Models 1 through 5 show that gender, compared to other variables except the speech and term variables, does a much better job of explaining the variation in the dependent variable.

Electorally safe MPs prefer to focus on a narrower range of issues. One potential reason behind this is that an electorally safe place in the party list may free MPs from electoral pressures in terms of issue attention. Models 2, 3 and 5 report that opposition MPs prefer to speak about a wider range of issues and that MPs from larger 
districts focus on a narrower range of issues. The finding that district magnitude is negatively associated with entropic agenda may come as a surprise, as more populated constituencies are arguably more heterogeneous and therefore more likely to produce a wide range of constituency issues. A possible explanation for this finding might appeal to the constituency differences in economic development, with smaller constituencies being less developed and thus requiring attention in a larger number of policy issues. Finally, models 2 and 5 show that issue diversity was lower in the $22^{\text {nd }}$ legislative term, as indicated by the term variable. All in all, these results lend strong support to the hypothesis that female parliamentarians attend to a wider range of issues than their male counterparts.

\subsubsection{Additional Analyses}

Given that female representatives constitute only 7 percent of all MPs in my dataset, I undertake additional analyses using different samples and dependent variables. First, I used the propensity score matching method to match a similar number of female representatives to their male counterparts based on their political and sociodemographic characteristics (i.e., the 'nearest neighbor matches'). This allowed me to compare 63 female and 54 male representatives with very similar characteristics. Results based on the propensity matching method support my original findings. Second, I have replicated my models using two alternative dependent variables. Although Shannon's entropy index has been widely used by political scientists (e.g., Jones and Baumgartner 2005; Alexandrova, Carammia and Timmermans 2012; Jennings, Bevan and John 2011), there are other diversity measures used by scholars from other disciplines. Most recently, Boydstun, Bevan and Thomas (2014) explored individual strengths and weaknesses of two commonly used diversity measures, Shannon's entropy and Herfindahl-Hirschman $(\mathrm{H}-\mathrm{H})$ Index, and concluded that the former is more sensitive to high and low values. For this reason, I replicated the empirical 
Table 5.2: The Effect of Gender on Entropic Agenda

\begin{tabular}{llllll}
\hline \hline & Model 1 & Model 2 & Model 3 & Model 4 & Model 5 \\
\hline Female & $0.111^{* * *}$ & $0.120^{* * *}$ & $0.141^{* * *}$ & $0.145^{* * *}$ & $0.111^{* *}$ \\
& $(0.053)$ & $(0.051)$ & $(0.054)$ & $(0.0549)$ & $(0.0526)$ \\
Speech $(\mathrm{log})$ & $0.368^{* * *}$ & $0.349^{* * *}$ & $0.353^{* * *}$ & $0.370^{* * *}$ & $0.351^{* * *}$ \\
& $(0.012)$ & $(0.013)$ & $(0.014)$ & $(0.0121)$ & $(0.0136)$ \\
Electoral Safety & $-0.027^{* * *}$ & $-0.0101^{*}$ & $-0.0152^{* * *}$ & $-0.0213^{* * *}$ & $-0.0094^{*}$ \\
& $(0.0048)$ & $(0.0057)$ & $(0.0058)$ & $(0.00564)$ & $(0.0057)$ \\
Localness & & & 0.0346 & 0.0365 & 0.0333 \\
Education & & & $(0.0284)$ & $(0.0283)$ & $(0.0279)$ \\
& & & 0.02 & -0.0326 & -0.0501 \\
Age & & & $(0.036)$ & $(0.0372)$ & $(0.0355)$ \\
& & & 0.0004 & 0.00150 & -0.0015 \\
District Magnitude & & $-0.0057^{* * *}$ & $-0.00430^{* *}$ & $-0.00138)$ & $(0.0013)$ \\
Opposition & & $(0.0017)$ & $(0.002)$ & $(0.0019)$ & $-0.0045^{* *}$ \\
& & $0.098^{* * *}$ & $0.0903^{* * *}$ & & $0.102^{* * *}$ \\
22nd Term & & $(0.029)$ & $(0.0307)$ & & $(0.0298)$ \\
& & $-0.171^{* * *}$ & & & $-0.179^{* * *}$ \\
Constant & & $(0.0231)$ & & & $(0.0238)$ \\
& $0.514^{* * *}$ & $0.636^{* * *}$ & $0.553^{* * *}$ & $0.522^{* * *}$ & $0.820^{* * *}$ \\
Observations & $(0.033)$ & $(0.035)$ & $(0.128)$ & $(0.130)$ & $(0.130)$ \\
R-squared & & & & & \\
\hline \hline
\end{tabular}

Robust standard errors in parentheses

$* * * p<0.01, * * p<0.05, * p<0.1$

models reported in Table 2 using the normalized H-H index and found supporting evidence for my hypothesis. Additionally, I have created an ordinal dependent variable by dividing the normalized H-H by two equal cut-points and estimated simulated probabilities for 'low', 'medium' and 'high' diversity outcomes for male and female representatives. According to this, switching from male to female while holding other variables constant at their means leads to substantively and significantly meaningful changes in the probability of having low (-53\%), medium (-12\%) and high-diversity scores $(+57 \%)$.

Finally, I have collected additional parliamentary speeches (over 4,000) from a 
new legislative term (1999-2002) to undertake additional analyses. I have included all female representatives (28) and randomly selected (195) male representatives from this period. As a result, with the addition of 223 representatives, my new sample consists of 1,323 MPs. These new male and female representatives are balanced on electoral safety, entropy score and speeches; descriptive statistics are reported in Tables B1 to B4 in the Appendix. I replicated my baseline model with this new sample and found strong support for my hypothesis. Results are reported in Table B.5 and B.6.

\subsection{Discussion}

A growing body of research examines the role of information processing on decisionmaking under various political conditions. Although an increasing number of scholars point to the importance of cognitive capacities of individuals in explaining macrophenomena, scant attention has been devoted to how individual human beings process incoming information (Jones 2017; Shaffer 2017; Thomas 2017). The present study aims to fill this gap by analyzing female-male differences in information processing in a parliamentary setting. Drawing on empirical findings in cognitive science research, I argue that female representatives should speak about a wider range of issues in the parliament due to lower cognitive threshold of urgency for policy problems. Results based on multivariate regressions indicate that female representatives do indeed speak about a wider range of issues in the parliament, a finding that is robust to alternative model specifications and robustness tests.

All in all, although the findings reported here are provocative they are clearly not definitive. More work needs to be done in identifying the differences between male and female representatives in how they process incoming information about societal and political issues in legislatures. Also, it is important to note that the research 
design utilized in this study does not allow us to distinguish between biological and social factors that shape female-male differences in political behavior. Experimental research designs in particular may prove useful in exploring causal mechanisms behind gender and/or sex differences in information processing. 


\section{Chapter 6}

\section{Conclusion}

That women differ from men in the way they process information about the environment surrounding them is a widely accepted argument in various fields of psychology. A considerable body of research has shown that women, compared with men, show more concern for societal issues and rely more heavily on social cues about the external environment. One implication of these differences, I argued, is that women attend to a wider range of issues facing their country. I test this hypothesis using the most comprehensive dataset of most important problem surveys and original datasets of legislative activities, and found strong evidence for the theses that (i) female respondents list a higher number of issues when asked about the most important problems facing their country, and (ii) female legislators speak about a wider range of issues in the parliament. I also found that women pay particular attention to issues related to care, harm and empowerment (i.e., 'compassion' issues, see Page and Shapiro 2010), and gender differences in policy priorities are mostly invariant across time.

The main contribution of this dissertation is two-fold: First, behavioral models of individual choice in the political process have long been at the core of theories about various macro phenomena. The proponents of the Punctuated Equilibrium Theory (PET) have emphasized the importance of cognitive capacities of individuals in issue 
attention, and reached the conclusion that human beings, along with the institutions and organizations they inhabit, tend to be disproportionate information processors (Jones 2001, 2017; Jones and Thomas 2017; Jones and Baumgartner 2005; Workman, Jones and Jochim 2009). That is, decision makers tend to under- and over-react to incoming information streams, as suggested by the bounded rationality framework (Simon 1983; Jones 2001, 2017). A bibliography of punctuated equilibrium studies shows that over 374 articles, books or book chapters related to PET have been published since the publication of Agendas and Instability in American Politics in 1993 (Baumgartner, Jones and Mortensen 2014). However, except few recent studies (see Shaffer 2017; Thomas 2017), little attempt has been made to explain individual-level differences in information processing. This dissertation makes the first comprehensive attempt to advance our knowledge of differences in information processing.

Secondly, by documenting empirical evidence that there are individual-level differences in issue-carrying capacity, this dissertation makes a major contribution to various strands of research in the study of political behavior. In The Nature and Origins of Mass Opinion, Zaller (1990, 49) famously argued that "individuals answer survey questions by averaging across the considerations that are immediately salient or accessible to them." However, studies focusing on issue voting have made no attempt to explore individual-level differences in 'averaging across the considerations that are immediately salient or accessible' to voters. Differences in empathizing and general social interest may help us explain whether particular groups of people are more susceptible to issue voting. For instance, brain-imaging studies have shown that women are more likely to encode emotional stimuli by consciously accessible means (see Canli et al. 2002 for an overview). If particular groups of people are more likely be influenced by societal problems due to differences in empathy and general social interest, then these differences may shape the way political elites design campaigns and party manifestos. 
The findings documented in this dissertation have important implications for several strands of research in political science. Firstly, research on voting behavior suggest that economic evaluations play a significantly larger role in men's voting choices compared to women (Welch and Hibbing 1992). As disproportionate information processors, individuals can attend to a small number of issues at a time (Jones 2001; Jones and Baumgartner 2005). Women's advantage in attending to a larger number of problems facing their countries may lead them to pay less attention to and rely less on economic cues. Stated differently, since increases in issue-carring capacity would come at the expense of attention to individual 'core issues' (Jennings et al. 2011), attention to a wider range of issues may result in decreased attention to economic cues, hence economic voting. Additionally, differences in individuals' issue-carring capacity may have important implications for vote choice independent of economic evaluations. Women's advantage in the identification of a wider range of problems facing the society may lead to differing levels of blame attributions and satisfaction with democracy. Specifically, citizens identifying a larger number of societal problems may expect more from the government. Surveys conducted in advanced countries reveal that women are more likely to call for government responsibility in dealing with problems facing their countries (World Values Survey, Wave 6) and more likely to express dissatisfaction with democracy (EES 1999).

As summarized previously, the main finding of this project is that women focus on a wider range of issues facing their society. If women indeed attend to a wider range of issues than their male counterparts, then women and men may have differing levels of blame attributions and satisfaction with democracy. Indeed, simple meancomparison tests based on the most recent wave (2010-2014) of the World Values Survey reveal that women attribute more responsibility to the government, rather than individual citizens $(p<0.001)$. Additionally, utilizing the European Election Study (EES) surveys conducted in 12 West European countries in 1999 (N=13,549), 
I estimate bivariate logistic regressions that predict dissatisfaction with democracy and found that women are significantly more likely than men to express dissatisfaction with democracy $(p<0.001)$.

Secondly, women's attention to a larger number of societal issues may result in growing entropic agenda in legislatures, party manifestos and election campaigns as women participate more in the political life. In a recent study, Greene and O'Brien (2016), for instance, found that increasing women representation in legislatures leads to a larger scope of issues represented on the manifesto. Similarly, increasing women representation in legislatures may result in the representation of a wider range of issues. Previous scholarship found that women differ significantly from men in policy priorities (Schwindt-Bayer 2006), though no evidence has been documented indicating whether these distinct policy priorities translate into a larger macro pattern at the party, legislative or country level. A systematic comparison of legislative agenda diversity in similar countries with varying levels of women representation may prove useful in advancing our understanding of whether agenda diversity at the individual level translates into legislative agenda diversity.

Another potential implication of these findings concerns the study of comparative public policy. In a recent work, Baumgartner and Jones (2015) argue that entropic information, diverse streams of incoming information, in representative institutions leads to problem discovery, as diverse viewpoints help reveal different aspects of societal problems. As such, increasing representation of women in legislatures may help alleviate the problem of systematic underreactions by bringing a wide range of issues into discussion. After all, policies in low-information societies with poor problem recognition and signal detection change more drastically (Baumgartner et al. 2017).

These findings have implications for gender studies as well. Previous scholarship found that women differ significantly from men in policy priorities (Swers 1998, 2001; Schwindt-Bayer 2006). Based on the findings reported in the present study, one might 
speculate that women do not simply care more about some issues (e.g., soft issues, see Bäck, Debus and Müller 2014), but instead have a higher issue-carrying capacity that allows them to pay attention to various types of issues (e.g., soft and other issues) simultaneously. Research on gender differences in policy priorities has utilized individual policy issues as dependent variables and failed to address potential femalemale differences in issue-carrying capacity. Such differences can be explained in part by systematic male-female differences in individuals' issue-carrying capacity.

Finally, future research should rely more on cognitive and behavioral foundations of human choice in political decision making processes. A wealth of research in cognitive sciences has shown the utility of moral, behavioral and cognitive roots of various political behaviors. A stronger connection between political science and other fields that involve human behavior is key to advancing our understanding of human choice. 


\section{Appendix A}

Table A.1: Summary Statistics

\begin{tabular}{lccccc}
\hline \hline & $\mathrm{N}$ & Mean & Std. Dev. & Min. & Max. \\
\hline Feminine Issues & 935,172 & 0.173 & 0.378 & 0 & 1 \\
Masculine Issues & 935,172 & 0.265 & 0.441 & 0 & 1 \\
Female & 935,172 & 0.522 & 0.499 & 0 & 1 \\
Republican & 935,172 & 0.269 & 0.443 & 0 & 1 \\
Democrat & 935,172 & 0.415 & 0.492 & 0 & 1 \\
Region: South & 847,684 & 0.295 & 0.456 & 0 & 1 \\
Age (log) & 905,108 & 3.801 & 0.381 & 2.890 & 4.615 \\
Education & 905,965 & 3.041 & 0.992 & 1 & 5 \\
Income Level & 710,429 & 2.538 & 1.083 & 1 & 4 \\
Democratic President & 935,172 & 0.483 & 0.499 & 1 & 1 \\
\hline
\end{tabular}


Table A.2: The Number of Respondents by Survey Organization

\begin{tabular}{lcc}
\hline \hline Survey Organization & Frequency & Percent \\
\hline ABC News & 5,306 & 0.57 \\
ABC/Washington Post & 13,437 & 1.44 \\
ANES & 37,072 & 3.96 \\
Associated Press & 1,499 & 0.16 \\
CBS News & 78,857 & 8.43 \\
CBS News / NYT & 148,512 & 15.88 \\
CCFR & 1,507 & 0.16 \\
Chilton Research Services & 35,564 & 3.80 \\
Decima Research & 1,000 & 0.11 \\
Harris Interactive & 1,003 & 0.11 \\
ICR & 4,977 & 0.53 \\
Ipsos & 5,036 & 0.54 \\
Los Angeles Times & 63,068 & 6.74 \\
NORC & 2,564 & 0.27 \\
New York Times & 6,071 & 0.65 \\
Princeton Survey Research Associate & 69,318 & 7.41 \\
Schulman, Ronca and Bucuvalas & 2,011 & 0.22 \\
Social Science Research Solutions & 6,168 & 0.66 \\
Stony Brook University & 4,992 & 0.53 \\
Gallup & 438,989 & 46.94 \\
Washington Post & 3,662 & 0.39 \\
Yankelovich Partners, Inc & 4,559 & 0.49 \\
\hline
\end{tabular}




\section{Appendix B}

Table B.1: Summary Statistics based on the New Sample (1999-2002, female only)

\begin{tabular}{lccccc}
\hline \hline & $\mathrm{N}$ & Mean & Std. Dev. & Min. & Max. \\
\hline Entropy & 28 & 1.294 & 0.454 & 0.572 & 2.247 \\
Speech (log) & 28 & 2.345 & 0.784 & 1.099 & 3.850 \\
Electoral Safety & 28 & 1.036 & 1.170 & 0 & 4 \\
District Magnitude & 28 & 12.75 & 7.797 & 2 & 24 \\
Opposition & 28 & 0.286 & 0.460 & 0 & 1 \\
\hline
\end{tabular}

Table B.2: Summary Statistics based on the New Sample (1999-2002, male only)

\begin{tabular}{lccccc}
\hline \hline & $\mathrm{N}$ & Mean & Std. Dev. & Min. & Max. \\
\hline Entropy & 195 & 1.292 & 0.621 & 0 & 2.525 \\
Speech $(\log )$ & 195 & 2.563 & 0.895 & 1.099 & 4.736 \\
Electoral Safety & 195 & 0.800 & 1.212 & 0 & 6 \\
District Magnitude & 195 & 9.862 & 5.982 & 2 & 24 \\
Opposition & 195 & 0.359 & 0.481 & 0 & 1 \\
\hline
\end{tabular}


Table B.3: Summary Statistics based on the Original Sample (2002-2011, female only)

\begin{tabular}{lccccc}
\hline & $\mathrm{N}$ & Mean & Std. Dev. & Min. & Max. \\
\hline Entropy & 68 & 1.416 & 0.448 & 0.315 & 2.525 \\
Speech (log) & 68 & 2.345 & 0.801 & 0.693 & 4.174 \\
Electoral Safety & 60 & 2.733 & 2.469 & 0 & 10 \\
Localness & 68 & 0.441 & 0.500 & 0 & 1 \\
Education & 68 & 2.941 & 0.237 & 2 & 3 \\
Age & 68 & 44.13 & 8.595 & 30 & 68 \\
District Magnitude & 68 & 17.04 & 10.11 & 2 & 31 \\
Opposition & 68 & 0.412 & 0.496 & 0 & 1 \\
$22^{\text {nd }}$ Term & 68 & 0.368 & 0.486 & 0 & 1 \\
\hline
\end{tabular}

Table B.4: Summary Statistics based on the Original Sample (2002-2011, male only)

\begin{tabular}{lccccc}
\hline \hline & $\mathrm{N}$ & Mean & Std. Dev. & Min. & Max. \\
\hline Entropy & 911 & 1.370 & 0.546 & 0 & 2.506 \\
Speech (log) & 911 & 2.493 & 1.088 & 0.693 & 5.883 \\
Electoral Safety & 886 & 2.157 & 2.627 & 0 & 15 \\
Localness & 911 & 0.663 & 0.473 & 0 & 1 \\
Education & 911 & 2.910 & 0.326 & 1 & 3 \\
Age & 911 & 50.00 & 8.433 & 30 & 83 \\
District Magnitude & 911 & 10.17 & 8.046 & 2 & 31 \\
Opposition & 911 & 0.372 & 0.484 & 0 & 1 \\
$22^{\text {nd }}$ Term & 911 & 0.508 & 0.500 & 0 & 1 \\
\hline
\end{tabular}


Table B.5: The Effect of Gender on Agenda Diversity (1999-2011)

\begin{tabular}{lcc}
\hline \hline & Model 3 & Model 4 \\
\hline Female & $0.0868^{* *}$ & $0.121^{* *}$ \\
& $(0.0419)$ & $(0.0412)$ \\
Speech (log) & $0.390^{* * *}$ & $0.368^{* * *}$ \\
& $(0.0112)$ & $(0.0128)$ \\
Electoral Safety & $-0.0223^{* * *}$ & $-0.00919^{*}$ \\
& $(0.00468)$ & $(0.00553)$ \\
District Magnitude & & $-0.00596^{* * *}$ \\
& & $(0.00161)$ \\
Opposition & & $0.117^{* * *}$ \\
& & $(0.0264)$ \\
22nd Term & & 0.0410 \\
23rd Term & & $0.0318)$ \\
Constant & & $(0.0312)$ \\
& $0.425^{* * *}$ & $0.372^{* * *}$ \\
Observations & $(0.0326)$ & $(0.0441)$ \\
R-squared & & \\
\hline
\end{tabular}

Table B.6: The Effect of Gender on Agenda Diversity (1999-2002 only)

\begin{tabular}{lcc}
\hline \hline & Model 3 & Model 4 \\
\hline Female & $0.125^{* *}$ & $0.132^{* *}$ \\
& $(0.0628)$ & $(0.0649)$ \\
Speech (log) & $0.535^{* * *}$ & $0.495^{* * *}$ \\
& $(0.0273)$ & $(0.0313)$ \\
Electoral Safety & $-0.0307^{*}$ & -0.0146 \\
& $(0.0184)$ & $(0.0215)$ \\
District Magnitude & & -0.00246 \\
& & $(0.00403)$ \\
Opposition & & $0.171^{* * *}$ \\
& & $(0.0588)$ \\
Constant & -0.0537 & -0.00292 \\
& $(0.0834)$ & $(0.0929)$ \\
Observations & & \\
R-squared & 223 & 223 \\
\hline
\end{tabular}




\section{Bibliography}

Adolphs, Ralph. 2003. "Cognitive neuroscience of human social behavior." Nature Reviews Neuroscience 4:165-178.

Adolphs, Ralph. 2009. "The social brain: neural basis of social knowledge." Annual review of psychology 60:693-716.

Alexandrova, Petya, Marcello Carammia \& Arco Timmermans. 2012. "Policy punctuations and issue diversity on the European Council agenda." Policy Studies Journal 40(1):69-88.

Allen, Richard L \& Fausto Izcaray. 1988. "Nominal agenda diversity in a media-rich, less-developed society." Communication Research 15(1):29-50.

Amen, Daniel G, Manuel Trujillo, David Keator, Derek V Taylor, Kristen Willeumier, Somayeh Meysami \& Cyrus A Raji. 2017. "Gender-Based Cerebral Perfusion Differences in 46,034 Functional Neuroimaging Scans." Journal of Alzheimer's Disease 60(2):605-614.

Anderson, John R \& Gordon H Bower. 2014. Human associative memory. Psychology press.

Applegate, Brandon K, Francis T Cullen \& Bonnie S Fisher. 2002. "Public views toward crime and correctional policies: Is there a gender gap?" Journal of Criminal Justice 30(2):89-100. 
Arceneaux, Kevin, Johanna Dunaway \& Stuart Soroka. 2018. "Elites are people, too: The effects of threat sensitivity on policymakers spending priorities." PloS one 13(4):e0193781.

Atkinson, Mary Layton, John Lovett \& Frank R Baumgartner. 2014. "Measuring the media agenda." Political Communication 31(2):355-380.

Ayata, Ayşe Güneş \& Fatma Tütüncü. 2008. "Critical Acts without a critical mass: The substantive representation of women in the Turkish parliament." Parliamentary Affairs 61(3):461-475.

Bäck, Hanna \& Marc Debus. 2016. Political parties, parliaments and legislative speechmaking. Springer.

Bäck, Hanna, Marc Debus \& Jochen Müller. 2014. "Who takes the parliamentary floor? The role of gender in speech-making in the Swedish Riksdag." Political Research Quarterly 67(3):504-518.

Bakan, David. 1966. "The duality of human existence: An essay on psychology and religion.".

Barabasi, Albert-Laszlo. 2005. "The origin of bursts and heavy tails in human dynamics." Nature 435(7039):207.

Barke, Richard P, Hank Jenkins-Smith \& Paul Slovic. 1997. "Risk perceptions of men and women scientists." Social Science Quarterly pp. 167-176.

Baron-Cohen, Simon. 2002. "The extreme male brain theory of autism." Trends in cognitive sciences 6(6):248-254.

Baron-Cohen, Simon. 2004. The Essential Difference: Men, Women and the Extreme Male Brain. Penguin UK. 
Baron-Cohen, Simon. 2010. Empathizing, systemizing, and the extreme male brain theory of autism. In Progress in brain research. Vol. 186 Elsevier pp. 167-175.

Baron-Cohen, Simon, Rebecca C Knickmeyer \& Matthew K Belmonte. 2005. "Sex differences in the brain: implications for explaining autism." Science 310(5749):819-823.

Baumann, Markus, Marc Debus \& Tristan Klingelhöfer. 2017. "Keeping Ones Seat: The Competitiveness of MP Renomination in Mixed-Member Electoral Systems." The Journal of Politics 79(3):979-994.

Baumgartner, Frank R \& Bryan D Jones. 1993. Agendas and Instability in American politics. University of Chicago Press.

Baumgartner, Frank R, Bryan D Jones \& Peter B Mortensen. 2014. "Punctuated equilibrium theory: Explaining stability and change in public policymaking." Theories of the policy process 8:59-103.

Baumgartner, Frank R, Christian Breunig, Christoffer Green-Pedersen, Bryan D Jones, Peter B Mortensen, Michiel Nuytemans \& Stefaan Walgrave. 2009. "Punctuated equilibrium in comparative perspective." American Journal of Political Science 53(3):603-620.

Bayliss, Andrew P, Giuseppe di Pellegrino \& Steven P Tipper. 2005. "Sex differences in eye gaze and symbolic cueing of attention." The Quarterly Journal of Experimental Psychology Section A 58(4):631-650.

Bendyna, Mary E, Tamara Finucane, Lynn Kirby, John P O'Donnell \& Clyde Wilcox. 1996. "Gender differences in public attitudes toward the Gulf War: A test of competing hypotheses." The Social Science Journal 33(1):1-22. 
Beutel, Ann M \& Margaret Mooney Marini. 1995. "Gender and Values." American Sociological Review pp. 436-448.

Billington, Jac, Simon Baron-Cohen \& Sally Wheelwright. 2007. "Cognitive style predicts entry into physical sciences and humanities: Questionnaire and performance tests of empathy and systemizing." Learning and Individual Differences $17(3): 260-268$.

Bird, Karen. 2005. "Gendering parliamentary questions." The British Journal of Politics 6 International Relations 7(3):353-370.

Block, Richard A, Peter A Hancock \& Dan Zakay. 2000. "Sex differences in duration judgments: A meta-analytic review." Memory $\&$ Cognition 28(8):1333-1346.

Boydstun, Amber E, Shaun Bevan \& Herschel F Thomas. 2014. "The importance of attention diversity and how to measure it." Policy Studies Journal 42(2):173-196.

Bradley, Margaret M, Maurizio Codispoti, Dean Sabatinelli \& Peter J Lang. 2001. "Emotion and motivation II: sex differences in picture processing." Emotion $1(3): 300$.

Bratton, Kathleen A \& Kerry L Haynie. 1999. "Agenda setting and legislative success in state legislatures: The effects of gender and race." The Journal of Politics 61(3):658-679.

Bratton, Kathleen A \& Leonard P Ray. 2002. "Descriptive representation, policy outcomes, and municipal day-care coverage in Norway." American Journal of Political Science pp. 428-437.

Brosnan, Mark, Melissa Hollinworth, Konstantina Antoniadou \& Marcus Lewton. 2014. "Is empathizing intuitive and systemizing deliberative?" Personality and Individual Differences 66:39-43. 
Brouard, Sylvain. 2013. "MPs' Issue Attention in Parliament: Evidence of a Stick-Slip Process of Attention Allocation in the French National Assembly." The Journal of Legislative Studies 19(2):246-260.

Burns, Nancy, Kay Lehman Schlozman \& Sidney Verba. 2001. The private roots of public action. Harvard University Press.

Byrd-Craven, Jennifer \& David C Geary. 2007. "Biological and evolutionary contributions to developmental sex differences." Reproductive biomedicine online $15: 12-22$.

Cahill, Larry. 2000. "Modulation of long-term memory storage in humans by emotional arousal: adrenergic activation and the amygdala." The amygdala .

Cahill, Larry, Melina Uncapher, Lisa Kilpatrick, Mike T Alkire \& Jessica Turner. 2004. "Sex-related hemispheric lateralization of amygdala function in emotionally influenced memory: an FMRI investigation." Learning 83 memory 11(3):261266.

Cahill, Larry, Richard J Haier, Nathan S White, James Fallon, Lisa Kilpatrick, Chris Lawrence, Steven G Potkin \& Michael T Alkire. 2001. "Sex-related difference in amygdala activity during emotionally influenced memory storage." Neurobiology of learning and memory 75(1):1-9.

Calero, Cecilia Ines, Alejo Salles, Mariano Semelman \& Mariano Sigman. 2013. "Age and gender dependent development of Theory of Mind in 6-to 8-years old children." Frontiers in human neuroscience 7:281.

Canli, Turhan, John E Desmond, Zuo Zhao \& John DE Gabrieli. 2002. "Sex differences in the neural basis of emotional memories." Proceedings of the National Academy of Sciences 99(16):10789-10794. 
Carey, John M \& Matthew Soberg Shugart. 1995. "Incentives to cultivate a personal vote: A rank ordering of electoral formulas." Electoral studies 14(4):417-439.

Celis, Karen \& Sarah Childs. 2008. "Introduction: The descriptive and substantive representation of women: New directions." Parliamentary Affairs 61(3):419-425.

Childs, Sarah \& Julie Withey. 2004. "Women representatives acting for women: sex and the signing of early day motions in the 1997 British parliament." Political Studies 52(3):552-564.

Childs, Sarah et al. 2004. New Labour's Women MPs: Women Representing Women. Routledge.

Chodorow, Nancy. 1978. "Mothering, object-relations, and the female oedipal configuration." Feminist Studies 4(1):137-158.

Christov-Moore, Leonardo, Elizabeth A Simpson, Gino Coudé, Kristina Grigaityte, Marco Iacoboni \& Pier Francesco Ferrari. 2014. "Empathy: Gender effects in brain and behavior." Neuroscience \&5 Biobehavioral Reviews 46:604-627.

Ciftci, Sabri \& Tevfik Murat Yildirim. 2017. "Hiding behind the party brand or currying favor with constituents: Why do representatives engage in different types of constituency-oriented behavior?" Party Politics p. 1354068817720438.

Connellan, Jennifer, Simon Baron-Cohen, Sally Wheelwright, Anna Batki \& Jag Ahluwalia. 2000. "Sex differences in human neonatal social perception." Infant behavior and Development 23(1):113-118.

Conover, Pamela Johnston. 1988. "Feminists and the gender gap." The Journal of Politics 50(4):985-1010.

Conover, Pamela Johnston \& Virginia Sapiro. 1993. "Gender, feminist consciousness, and war." American Journal of Political Science pp. 1079-1099. 
Conway, Mary Margaret. 2000. Political participation in the United States. Washington, DC: CQ Press.

Darley, William K \& Robert E Smith. 1995. "Gender differences in information processing strategies: An empirical test of the selectivity model in advertising response." Journal of advertising 24(1):41-56.

David, B Hill. 1983. "Women state legislators and party voting on the ERA." Social Science Quarterly 64(2):318.

Davis, Michael \& Paul J Whalen. 2001. "The amygdala: vigilance and emotion." Molecular psychiatry 6(1):13.

Decety, Jean \& Philip L Jackson. 2004. "The functional architecture of human empathy." Behavioral and cognitive neuroscience reviews 3(2):71-100.

DeSoto, M Catherine, Jennifer Bumgardner, Abbie Close \& David C Geary. 2007. "Investigating the role of hormones in theory of mind." North American Journal of Psychology 9(3):535-544.

Diamond, Irene. 1977. Sex roles in the state house. Yale University Press.

Dodson, Debra L. 2006. The impact of women in Congress. Oxford University Press on Demand.

Donges, Uta-Susan, Anette Kersting \& Thomas Suslow. 2012. "Women's greater ability to perceive happy facial emotion automatically: gender differences in affective priming." PLoS One 7(7):e41745.

Dykiert, Dominika, Catharine R Gale \& Ian J Deary. 2009. "Are apparent sex differences in mean IQ scores created in part by sample restriction and increased male variance?" Intelligence 37(1):42-47. 
Eagly, Alice H. 2009. "The his and hers of prosocial behavior: An examination of the social psychology of gender." American Psychologist 64(8):644.

Eagly, Alice H, Amanda B Diekman, Mary C Johannesen-Schmidt \& Anne M Koenig. 2004. "Gender gaps in sociopolitical attitudes: A social psychological analysis." Journal of personality and social psychology 87(6):796.

Eagly, Alice H \& Maureen Crowley. 1986. "Gender and helping behavior: A metaanalytic review of the social psychological literature." Psychological bulletin 100(3):283.

Eagly, Alice H \& Valerie J Steffen. 1986. "Gender and aggressive behavior: a meta-analytic review of the social psychological literature." Psychological bulletin 100(3):309.

Eichenberg, Richard C. 2003. "Gender differences in public attitudes toward the use of force by the United States, 1990-2003." International Security 28(1):110-141.

Epp, Derek A \& Frank R Baumgartner. 2017. "Complexity, capacity, and budget punctuations." Policy Studies Journal 45(2):247-264.

Fazio, Russell H \& Carol J Williams. 1986. "Attitude accessibility as a moderator of the attitude-perception and attitude-behavior relations: An investigation of the 1984 presidential election." Journal of personality and social psychology $51(3): 505$.

Fazio, Russell H, David M Sanbonmatsu, Martha C Powell \& Frank R Kardes. 1986. "On the automatic activation of attitudes." Journal of personality and social psychology 50(2):229.

Fiske, Susan T, Richard R Lau \& Richard A Smith. 1990. "On the varieties and utilities of political expertise." Social Cognition 8(1):31. 
Fite, David, Marc Genest \& Clyde Wilcox. 1990. "Gender differences in foreign policy attitudes: A longitudinal analysis." American Politics Quarterly 18(4):492-513.

Flynn, James, Paul Slovic \& Chris K Mertz. 1994. "Gender, race, and perception of environmental health risks." Risk analysis 14(6):1101-1108.

Focquaert, Farah, Megan S Steven, George L Wolford, Albina Colden \& Michael S Gazzaniga. 2007. "Empathizing and systemizing cognitive traits in the sciences and humanities." Personality and Individual Differences 43(3):619-625.

Fujita, Frank, Ed Diener \& Ed Sandvik. 1991. "Gender differences in negative affect and well-being: the case for emotional intensity." Journal of personality and social psychology 61(3):427.

Funk, Kendall D. 2015. "Gendered governing? Womens leadership styles and participatory institutions in Brazil." Political Research Quarterly 68(3):564-578.

Funk, Kendall D \& Andrew Q Philips. 2018. "Representative Budgeting: Women Mayors and the Composition of Spending in Local Governments." Political Research Quarterly p. 1065912918775237.

Geary, David C. 1998. Male, female: The evolution of human sex differences. Washington, DC, US: American Psychological Association.

Geary, David C. 2005. The origin of mind: Evolution of brain, cognition, and general intelligence. American Psychological Association.

Geary, David C. 2006. "Sex differences in social behavior and cognition: Utility of sexual selection for hypothesis generation." Hormones and Behavior 49(3):273275 .

Geary, David C \& Mark V Flinn. 2002. "Sex differences in behavioral and hormonal response to social threat: commentary on Taylor et al.(2000).". 
Gidengil, Elisabeth, André Blais, Richard Nadeau \& Neil Nevitte. 2003. "Women to the left? Gender differences in political beliefs and policy preferences." Women and electoral politics in Canada pp. 140-159.

Gilens, Martin. 2009. Why Americans hate welfare: Race, media, and the politics of antipoverty policy. University of Chicago Press.

Gilens, Martin \& Benjamin I Page. 2014. "Testing theories of American politics: Elites, interest groups, and average citizens." Perspectives on politics 12(3):564581.

Goldenfeld, Nigel, Simon Baron-Cohen \& Sally Wheelwright. 2005. "Empathizing and systemizing in males, females and autism." Clinical Neuropsychiatry 2(6):338345.

Goodwin, Jeff, James M Jasper \& Francesca Polletta. 2009. Passionate politics: Emotions and social movements. University of Chicago Press.

Greene, Zachary \& Diana Z O’Brien. 2016. "Diverse parties, diverse agendas? Female politicians and the parliamentary party's role in platform formation." European Journal of Political Research 55(3):435-453.

Gwartney-Gibbs, Patricia A \& Denise H Lach. 1991. "Sex differences in attitudes toward nuclear war." Journal of Peace Research 28(2):161-174.

Hall, Judith A. 1978. "Gender effects in decoding nonverbal cues." Psychological bulletin 85(4):845.

Halpern, Diane F. 1997. "Sex differences in intelligence: Implications for education." American Psychologist 52(10):1091.

Halpern, Diane F. 2013. Sex differences in cognitive abilities. Psychology Press. 
Halpern, Diane F \& Mary L LaMay. 2000. "The smarter sex: A critical review of sex differences in intelligence." Educational Psychology Review 12(2):229-246.

Hamann, Stephan. 2005. "Sex differences in the responses of the human amygdala." The Neuroscientist 11(4):288-293.

Hamann, Stephan \& Turhan Canli. 2004. "Individual differences in emotion processing." Current opinion in neurobiology 14(2):233-238.

Hannagan, Rebecca J, Levente Littvay \& Sebastian Adrian Popa. 2014. "Theorizing Sex Differences in Political Knowledge: Insights from a Twin Study." Politics \& Gender 10(1):89-114.

Happé, Francesca GE. 1995. "The role of age and verbal ability in the theory of mind task performance of subjects with autism." Child development 66(3):843-855.

Harshman, Richard A \& Allan Paivio. 1987. "'Paradoxical” sex differences in selfreported imagery." Canadian Journal of Psychology/Revue canadienne de psychologie 41(3):287.

Hatemi, Peter K, John R Hibbing, Sarah E Medland, Matthew C Keller, John R Alford, Kevin B Smith, Nicholas G Martin \& Lindon J Eaves. 2010. "Not by twins alone: Using the extended family design to investigate genetic influence on political beliefs." American Journal of Political Science 54(3):798-814.

Hatemi, Peter K \& Rose McDermott. 2012. "A neurobiological approach to foreign policy analysis: Identifying individual differences in political violence." Foreign Policy Analysis 8(2):111-129.

Hedges, Larry V \& Amy Nowell. 1995. "Sex differences in mental test scores, variability, and numbers of high-scoring individuals." Science 269(5220):41-45. 
Heffington, Colton, Brandon Beomseob Park \& Laron K Williams. 2017. "The Most Important Problem Dataset (MIPD): a new dataset on American issue importance." Conflict Management and Peace Science p. 0738894217691463.

Heilman, Madeline E. 2001. "Description and prescription: How gender stereotypes prevent women's ascent up the organizational ladder." Journal of social issues $57(4): 657-674$.

Herek, Gregory M. 2002. "Gender gaps in public opinion about lesbians and gay men." Public Opinion Quarterly 66(1):40-66.

Herlitz, Agneta, Lars-Göran Nilsson \& Lars Bäckman. 1997. "Gender differences in episodic memory." Memory \& cognition 25(6):801-811.

Holsti, Ole R \& James N Rosenau. 1981. "The foreign policy beliefs of women in leadership positions." The Journal of Politics 43(2):326-347.

Hooghe, Marc \& Dietlind Stolle. 2004. "Good girls go to the polling booth, bad boys go everywhere: Gender differences in anticipated political participation among American fourteen-year-olds." Women \& Politics 26(3-4):1-23.

Huddy, Leonie \& Nayda Terkildsen. 1993. "Gender stereotypes and the perception of male and female candidates." American Journal of Political Science pp. 119-147.

Hurwitz, Jon \& Shannon Smithey. 1998. "Gender differences on crime and punishment." Political Research Quarterly 51(1):89-115.

Hyde, Janet Shibley. 2005. "The gender similarities hypothesis." American psychologist 60(6):581.

Ibanez, Agustin, David Huepe, René Gempp, Virna Gutiérrez, Alvaro Rivera-Rei \& Maria Isabel Toledo. 2013. "Empathy, sex and fluid intelligence as predictors of theory of mind." Personality and Individual Differences 54(5):616-621. 
Inglehart, Ronald \& Pippa Norris. 2000. "The developmental theory of the gender gap: Womens and mens voting behavior in global perspective." International Political Science Review 21(4):441-463.

Jacob, Suraj. 2014. "Gender and legislative performance in India." Politics $\&$ Gender 10(2):236-264.

Jennings, Will, Shaun Bevan, Arco Timmermans, Gerard Breeman, Sylvain Brouard, Laura Chaqués-Bonafont, Christoffer Green-Pedersen, Peter John, Peter B Mortensen \& Anna M Palau. 2011. "Effects of the core functions of government on the diversity of executive agendas." Comparative Political Studies 44(8):10011030.

Jennings, Will, Shaun Bevan \& Peter John. 2011. "The agenda of British Government: the speech from the Throne, 1911-2008." Political Studies 59(1):74-98.

Jones, Bryan D. 1994. Reconceiving decision-making in democratic politics: Attention, choice, and public policy. University of Chicago Press.

Jones, Bryan D. 2001. Politics and the architecture of choice: Bounded rationality and governance. University of Chicago Press.

Jones, Bryan D \& Frank R Baumgartner. 2004. "A model of choice for public policy." Journal of Public Administration Research and Theory 15(3):325-351.

Jones, Bryan D \& Frank R Baumgartner. 2005. The politics of attention: How government prioritizes problems. University of Chicago Press.

Jones, Bryan D \& Frank R Baumgartner. 2012. "From there to here: Punctuated equilibrium to the general punctuation thesis to a theory of government information processing." Policy Studies Journal 40(1):1-20. 
Jones, Bryan D, Frank R Baumgartner, Christian Breunig, Christopher Wlezien, Stuart Soroka, Martial Foucault, Abel François, Christoffer Green-Pedersen, Chris Koski, Peter John et al. 2009. "A general empirical law of public budgets: A comparative analysis." American Journal of Political Science 53(4):855-873.

Jones, Bryan D, Tracy Sulkin \& Heather A Larsen. 2003. "Policy punctuations in American political institutions." American Political Science Review 97(1):151169.

Jost, John T, H Hannah Nam, David M Amodio \& Jay J Van Bavel. 2014. "Political neuroscience: The beginning of a beautiful friendship." Political Psychology $35(\mathrm{~S} 1): 3-42$.

Kirkpatrick, Jeane J. 1974. Political woman. Basic Books (AZ).

Kittilson, Miki Caul. 2008. "Representing women: The adoption of family leave in comparative perspective." The Journal of Politics 70(2):323-334.

Korkmaz, Baris. 2011. "Theory of mind and neurodevelopmental disorders of childhood." Pediatr Res 69(5 Pt 2):101R-8R.

Kozhevnikov, Maria. 2007. "Cognitive styles in the context of modern psychology: Toward an integrated framework of cognitive style." Psychological bulletin 133(3):464.

Krosnick, Jon A \& Michael A Milburn. 1990. "Psychological determinants of political opinionation." Social Cognition 8(1):49.

Lakoff, George. 2008. The political mind: why you can't understand 21st-century politics with an 18th-century brain. Penguin. 
Laver, Michael, Kenneth Benoit \& John Garry. 2003. "Extracting policy positions from political texts using words as data." American Political Science Review 97(2):311-331.

Lawson, John, Simon Baron-Cohen \& Sally Wheelwright. 2004. "Empathising and systemising in adults with and without Asperger Syndrome." Journal of autism and developmental disorders 34(3):301-310.

Leal, David L. 2005. "American public opinion toward the military: differences by race, gender, and class?" Armed Forces $\mathcal{G}$ Society 32(1):123-138.

Lieberman, Matthew D. 2000. "Intuition: a social cognitive neuroscience approach." Psychological bulletin 126(1):109.

Lieberman, Matthew D, Darren Schreiber \& Kevin N Ochsner. 2003. "Is political cognition like riding a bicycle? How cognitive neuroscience can inform research on political thinking." Political Psychology 24(4):681-704.

Lindblom, Charles E. 1959. "The Science of 'Muddling Through'." Public Administration Review 18:79-88.

Lyness, Karen S \& Madeline E Heilman. 2006. "When fit is fundamental: Performance evaluations and promotions of upper-level female and male managers." Journal of Applied Psychology 91(4):777.

Maccoby, Eleanor E \& Carol N Jacklin. 1974. "Myth, reality and shades of gray: What we know and don't know about sex differences." Psychology Today 8(7):109-112.

Manson, Christopher \& Mark Winterbottom. 2012. "Examining the association between empathising, systemising, degree subject and gender." Educational Studies 38(1):73-88. 
Marcus, George E. 2010. Sentimental citizen: Emotion in democratic politics. Penn State Press.

McClure, Erin B. 2000. "A meta-analytic review of sex differences in facial expression processing and their development in infants, children, and adolescents." Psychological bulletin 126(3):424.

McCombs, Maxwell \& Donald Shaw. 1977. "The emergence of American political issues." St. Paul, Minessota .

McCombs, Maxwell \& Jian-Hua Zhu. 1995. "Capacity, diversity, and volatility of the public agenda: Trends from 1954 to 1994." Public Opinion Quarterly 59(4):495525.

McGivern, Robert F, J Patrick Huston, Desiree Byrd, Tina King, Greg J Siegle \& Judy Reilly. 1997. "Sex differences in visual recognition memory: support for a sex-related difference in attention in adults and children." Brain and cognition 34(3):323-336.

Meeks, Lindsey. 2012. "Is she man enough? Women candidates, executive political offices, and news coverage." Journal of communication 62(1):175-193.

Meyers-Levy, Joan. 1989. Gender Differences in Information Processing: A Selectivity Interpretation. ed. Patricia Cafferata and Alice Tybout, Lexington, MA: Lexington.

Meyers-Levy, Joan \& Brian Sternthal. 1991. "Gender differences in the use of message cues and judgments." Journal of marketing research pp. 84-96.

Meyers-Levy, Joan \& Durairaj Maheswaran. 1991. "Exploring differences in males' and females' processing strategies." Journal of Consumer Research 18(1):63-70. 
Mezey, Susan Gluck. 1978. "Support for women's rights policy: An analysis of local politicians." American Politics Quarterly 6(4):485-497.

Miller, Scott A. 2009. "Childrens understanding of second-order mental states." Psychological bulletin 135(5):749.

Mondak, Jeffery J \& Karen D Halperin. 2008. "A framework for the study of personality and political behaviour." British Journal of Political Science 38(2):335-362.

Mortensen, Peter B. 2005. "Policy punctuations in Danish local budgeting." Public Administration 83(4):931-950.

Neumayer, Eric \& Thomas Plümper. 2017. Robustness Tests for Quantitative Research. Cambridge University Press.

Newell, Allen, Herbert Alexander Simon et al. 1972. Human problem solving. Vol. 104 Prentice-Hall Englewood Cliffs, NJ.

Norrander, Barbara. 1999. "The evolution of the gender gap." The Public Opinion Quarterly 63(4):566-576.

Ochsner, Kevin N \& Matthew D Lieberman. 2001. "The emergence of social cognitive neuroscience." American Psychologist 56(9):717.

Oxley, Douglas R, Kevin B Smith, John R Alford, Matthew V Hibbing, Jennifer L Miller, Mario Scalora, Peter K Hatemi \& John R Hibbing. 2008. "Political attitudes vary with physiological traits." science 321(5896):1667-1670.

Page, Benjamin I \& Robert Y Shapiro. 2010. The rational public: Fifty years of trends in Americans' policy preferences. University of Chicago Press.

Parsons, Talcot \& Robert F. Bales. 1955. Family, socialization and interaction process. Glencoe, IL: Free Press. 
Peter, Jochen \& Claes H De Vreese. 2003. "Agenda-rich, agenda-poor: A crossnational comparative investigation of nominal and thematic public agenda diversity." International Journal of Public Opinion Research 15(1):44-64.

Poggione, Sarah. 2004. "Exploring gender differences in state legislators policy preferences." Political Research Quarterly 57(2):305-314.

Popkin, Samuel L. 1994. The reasoning voter: Communication and persuasion in presidential campaigns. University of Chicago Press.

Preston, Stephanie D \& Frans BM De Waal. 2002. "Empathy: Its ultimate and proximate bases." Behavioral and brain sciences 25(1):1-20.

Proksch, Sven-Oliver \& Jonathan B Slapin. 2010. "Position taking in European Parliament speeches." British Journal of Political Science 40(3):587-611.

Rae Atkeson, Lonna \& Ronald B Rapoport. 2003. "The more things change the more they stay the same: Examining gender differences in political attitude expression, 1952-2000." Public Opinion Quarterly 67(4):495-521.

Rapoport, Ronald B, Walter J Stone \& Alan I Abramowitz. 1990. "Sex and the caucus participant: The gender gap and presidential nominations." American Journal of Political Science pp. 725-740.

Reingold, Beth. 2000. Representing women: Sex, gender, and legislative behavior in Arizona and California. Univ of North Carolina Press.

Rudman, Laurie A. 1998. "Self-promotion as a risk factor for women: the costs and benefits of counterstereotypical impression management." Journal of personality and social psychology 74(3):629.

Rudman, Laurie A \& Julie E Phelan. 2008. "Backlash effects for disconfirming gender stereotypes in organizations." Research in organizational behavior 28:61-79. 
Rushton, J Philippe, David W Fulker, Michael C Neale, David KB Nias \& Hans J Eysenck. 1986. "Altruism and aggression: the heritability of individual differences." Journal of personality and social psychology 50(6):1192.

Saint-German, Michelle A. 1989. "Does their difference make a difference? The impact of women on public policy in the Arizona legislature." Social Science Quarterly 70(4):956.

Savic, Ivanka, Alicia Garcia-Falgueras \& Dick F Swaab. 2010. Sexual differentiation of the human brain in relation to gender identity and sexual orientation. In Progress in brain research. Vol. 186 Elsevier pp. 41-62.

Schreiber, Darren, Greg Fonzo, Alan N Simmons, Christopher T Dawes, Taru Flagan, James H Fowler \& Martin P Paulus. 2013. "Red brain, blue brain: Evaluative processes differ in Democrats and Republicans." PLoS one 8(2):e52970.

Schulte-Rüther, Martin, Hans J Markowitsch, N Jon Shah, Gereon R Fink \& Martina Piefke. 2008. "Gender differences in brain networks supporting empathy." Neuroimage 42(1):393-403.

Schwindt-Bayer, Leslie A. 2006. "Still supermadres? Gender and the policy priorities of Latin American legislators." American Journal of Political Science 50(3):570585.

Seidlitz, Larry \& Ed Diener. 1998. "Sex differences in the recall of affective experiences." Journal of personality and social psychology 74(1):262.

Shaffer, Robert. 2017. "Cognitive load and issue engagement in congressional discourse." Cognitive Systems Research 44:89-99. 
Shapiro, Robert Y \& Harpreet Mahajan. 1986. "Gender Differences in Policy Preferences: A Summary of Trends from the 1960s to the 1980s." Public Opinion Quarterly 50(1):42-61.

Sheffer, Lior, Peter John Loewen, Stuart Soroka, Stefaan Walgrave \& Tamir Sheafer. 2018. "Nonrepresentative representatives: an experimental study of the decision making of elected politicians." American Political Science Review 112(2):302321.

Sidanius, Jim, Shana Levin, James Liu \& Felicia Pratto. 2000. "Social dominance orientation, anti-egalitarianism and the political psychology of gender: An extension and cross-cultural replication." European journal of social psychology 30(1):41-67.

Simon, Herbert A. 1978. "Information-processing theory of human problem solving." Handbook of learning and cognitive processes 5:271-295.

Simon, Herbert A. 1979. "Rational decision making in business organizations." The American economic review 69(4):493-513.

Simon, Herbert A. 1985. "Human nature in politics: The dialogue of psychology with political science." American Political Science Review 79(2):293-304.

Simon, Herbert A. 2013. Administrative behavior. Simon and Schuster.

Singer, Tania, Ben Seymour, John P O'doherty, Klaas E Stephan, Raymond J Dolan \& Chris D Frith. 2006. "Empathic neural responses are modulated by the perceived fairness of others." Nature 439(7075):466.

Slapin, Jonathan B \& Sven-Oliver Proksch. 2010. "Look whos talking: Parliamentary debate in the European Union." European Union Politics 11(3):333-357. 
Slovic, Paul, James Flynn, CK Mertz \& L Mullican. 1993. "Health-risk perception in Canada.".

Smith, Kevin, John R Alford, Peter K Hatemi, Lindon J Eaves, Carolyn Funk \& John R Hibbing. 2012. "Biology, ideology, and epistemology: how do we know political attitudes are inherited and why should we care?" American Journal of Political Science 56(1):17-33.

Soroka, Stuart, Elisabeth Gidengil, Patrick Fournier \& Lilach Nir. 2016. "Do Women and Men Respond Differently to Negative News?" Politics \& Gender 12(2):344368.

Steger, Mary Ann E \& Stephanie L Witt. 1989. "Gender differences in environmental orientations: a comparison of publics and activists in Canada and the US." Western Political Quarterly 42(4):627-649.

Stern, Paul C, Thomas Dietz \& Linda Kalof. 1993. "Value orientations, gender, and environmental concern." Environment and behavior 25(5):322-348.

Sternberg, Robert J \& Elena L Grigorenko. 1997. "Are cognitive styles still in style?" American psychologist 52(7):700.

Stevens, Jennifer S \& Stephan Hamann. 2012. "Sex differences in brain activation to emotional stimuli: a meta-analysis of neuroimaging studies." Neuropsychologia $50(7): 1578-1593$.

Stoet, Gijsbert \& David C Geary. 2018. "The gender-equality paradox in science, technology, engineering, and mathematics education." Psychological science 29(4):581-593. 
Swers, Michele. 2001. "Understanding the policy impact of electing women: Evidence from research on congress and state legislatures." PS: Political Science and Politics 34(2):217-220.

Swers, Michele L. 1998. "Are women more likely to vote for women's issue bills than their male colleagues?" Legislative Studies Quarterly pp. 435-448.

Taber, Charles S. 2003. "Information processing and public opinion." Oxford handbook of political psychology pp. 433-476.

Taylor, Shelley E, Laura Cousino Klein, Brian P Lewis, Tara L Gruenewald, Regan AR Gurung \& John A Updegraff. 2000. "Biobehavioral responses to stress in females: tend-and-befriend, not fight-or-flight." Psychological review 107(3):411.

Theodoridis, Alexander G \& Amy J Nelson. 2012. "Of BOLD claims and excessive fears: A call for caution and patience regarding political neuroscience." Political Psychology 33(1):27-43.

Thomas, Herschel F. 2017. "Modeling contagion in policy systems." Cognitive Systems Research 44:74-88.

Thomas, Sue \& Susan Welch. 1991. "The impact of gender on activities and priorities of state legislators." Western Political Quarterly 44(2):445-456.

Thompson, Ashley E \& Daniel Voyer. 2014. "Sex differences in the ability to recognise non-verbal displays of emotion: A meta-analysis." Cognition and Emotion 28(7):1164-1195.

Tourangeau, Roger \& Kenneth A Rasinski. 1988. "Cognitive processes underlying context effects in attitude measurement." Psychological bulletin 103(3):299. 
Verhulst, Brad, Lindon J Eaves \& Peter K Hatemi. 2012. "Correlation not causation: The relationship between personality traits and political ideologies." American journal of political science 56(1):34-51.

Wanta, Wayne, Pu-tsung King \& Maxwell E McCombs. 1995. "A comparison of factors influencing issue diversity in the US and Taiwan." International Journal of Public Opinion Research 7(4):353-365.

Welch, Susan. 1985. "Are women more liberal than men in the US Congress?" Legislative Studies Quarterly pp. 125-134.

Welch, Susan \& John Hibbing. 1992. "Financial conditions, gender, and voting in American national elections." The Journal of Politics 54(1):197-213.

Werner, Emmy E. 1968. "Women in the state legislatures." Western Political Quarterly 21(1):40-50.

West, Robin L, Thomas H Crook \& Kristina L Barron. 1992. "Everyday memory performance across the life span: Effects of age and noncognitive individual differences." Psychology and aging 7(1):72.

Westen, Drew. 2008. The political brain: The role of emotion in deciding the fate of the nation. PublicAffairs.

Wheelwright, Sally, Simon Baron-Cohen, Nigel Goldenfeld, Joe Delaney, Debra Fine, Richard Smith, Leonora Weil \& Akio Wakabayashi. 2006. "Predicting autism spectrum quotient (AQ) from the systemizing quotient-revised (SQ-R) and empathy quotient (EQ)." Brain research 1079(1):47-56.

Wildavsky, Aaron B. 1964. Politics of the Budgetary Process. Little, Brown. 
Witkin, Herman A \& Solomon E Asch. 1948. "Studies in space orientation. IV. Further experiments on perception of the upright with displaced visual fields." Journal of experimental psychology 38(6):762.

Wood, Wendy \& Alice H Eagly. 2012. Biosocial construction of sex differences and similarities in behavior. In Advances in experimental social psychology. Vol. 46 Elsevier pp. 55-123.

Workman, Samuel, Bryan D Jones \& Ashley E Jochim. 2009. "Information processing and policy dynamics." Policy Studies Journal 37(1):75-92.

Yildirim, Tevfik Murat, Gülnur Kocapınar \& Yüksel Alper Ecevit. 2017. "Staying active and focused? The effect of parliamentary performance on candidate renomination and promotion." Party Politics p. 1354068817740338.

Yonker, Julie E, Elias Eriksson, Lars-Göran Nilsson \& Agneta Herlitz. 2003. "Sex differences in episodic memory: Minimal influence of estradiol." Brain and cognition 52(2):231-238.

Zahn-Waxler, Carolyn, JoAnn L Robinson \& Robert N Emde. 1992. "The development of empathy in twins." Developmental psychology 28(6):1038.

Zaller, John. 1990. "Political awareness, elite opinion leadership, and the mass survey response." Social Cognition 8(1):125.

Zaller, John. 1992. The nature and origins of mass opinion. Cambridge university press.

Zaller, John \& Stanley Feldman. 1992. "A simple theory of the survey response: Answering questions versus revealing preferences." American journal of political science pp. 579-616. 
Zhu, Jian-Hua. 1992. "Issue competition and attention distraction: A zero-sum theory of agenda-setting." Journalism Quarterly 69(4):825-836. 


\section{VITA}

Tevfik Murat Yildirim was born in Istanbul, Turkey. He studied economics and political science in Istanbul, Bologna and Milan prior to coming to Missouri. Murat received his doctoral degree from University of Missouri in July 2018. His research broadly focuses on parliamentary politics and behavioral foundations of decisionmaking (elite and mass). In Fall 2018, Murat will join the Department of Political Science at University of California, Merced as a Lecturer. 